\title{
Reflective properties of white sea ice and snow
}

\author{
Aleksey Malinka ${ }^{1}$, Eleonora Zege ${ }^{1}$, Georg Heygster ${ }^{2}$, and Larysa Istomina ${ }^{2}$ \\ ${ }^{1}$ Institute of Physics, National Academy of Sciences of Belarus, 220072, pr. Nezavisimosti 68, Minsk, Belarus \\ ${ }^{2}$ Institute of Environmental Physics, University of Bremen, O. Hahn Allee 1, 28359 Bremen, Germany
}

Correspondence to: Aleksey Malinka (mal@light.basnet.by)

Received: 14 June 2016 - Published in The Cryosphere Discuss.: 7 July 2016

Revised: 22 September 2016 - Accepted: 5 October 2016 - Published: 2 November 2016

\begin{abstract}
White ice (ice with a highly scattering granular layer on top of its surface) and snow-covered ice occupy a large part of the sea ice area in the Arctic, the former in summer, the latter in the cold period. The inherent optical properties (IOPs) and the reflectance of these types of ice are considered from the point of view of the light scattering and radiative transfer theories. The IOPs - the extinction and absorption coefficients and the scattering phase function - are derived with the assumption that both the snow cover and the scattering layer of white ice are random mixtures of air and ice with the characteristic grain size significantly larger than the wavelength of incident light. Simple analytical formulas are put forward to calculate the bidirectional reflectance factor (BRF), albedo at direct incidence (the directionalhemispherical reflectance), and albedo at diffuse incidence (the bihemispherical reflectance). The optical model developed is verified with the data of the in situ measurements made during the R/V Polarstern expedition ARK-XXVII/3 in 2012 .
\end{abstract}

\section{Introduction}

Ice cover is the main factor governing the radiative budget in the Arctic (Curry et al., 1995; Eicken et al., 2004; Køltzow, 2007; Pirazzini, 2008; Shindell and Faluvegi, 2009; Serreze et al., 2011). Monitoring its state, including remote sensing, is of great importance, especially in times of the strong environmental changes we see nowadays (Serreze et al., 2000; Dethloff et al., 2006; Perovich et al., 2008; Pistone et al., 2014). The changes in the Arctic sea ice are particularly noticeable in summertime, when solar light controls the processes of sea ice transformation. It is also the season when satellite optical sensors are able to deliver information about polar regions. Our goal here is to develop a physical model of the reflective properties of summer ice, which is essential for the development of satellite remote sensing methods, as well as for the correct interpretation of the results of field measurements for understanding the physics of ice.

There is a great variety of sea ice types (Bogorodskii, 1970; Byshuev et al., 1974; Untersteiner, 1990; Perovich et al., 2009; Nicolaus et al., 2010; Sea Ice Nomenclature, 2014). "White ice" is not a strict term from the nomenclature; rather it puts together the various types of ice with high albedo and got its name due to its white appearance, produced by a highly scattering top layer (Grenfell and Maykut, 1977; Perovich, 1996). This layer is formed after meltwater has drained off from the surface elevations into the depressions. It consists of ice grains on the order of millimeters in size and, thus, can be described within the same approach as snow, but with larger grains (see Fig. 1). This layer provides stable high reflectance and, in fact, determines the reflective properties of white ice (Grenfell and Maykut, 1977; Perovich, 1996; Perovich et al., 2002; Herzfeld et al., 2006). White ice and snow are the brightest surfaces in the Arctic, which occupy a large part of the sea ice area, the former in the period of melting, the latter in the cold period (Grenfell and Maykut, 1977; Perovich et al., 2002). That is why it is so important to characterize their reflective properties accurately, especially with regard to monitoring the ice field albedo and melting processes from optical satellite observations (Sellers et al., 1995; Herzfeld et al., 2006; Tschudi et al., 2008; Rösel et al., 2012; Warren, 2013; Zege et al., 2015).

\section{Inherent optical properties}

An optical model of any medium is specified on the basis of some microphysical model. The common way to model the 


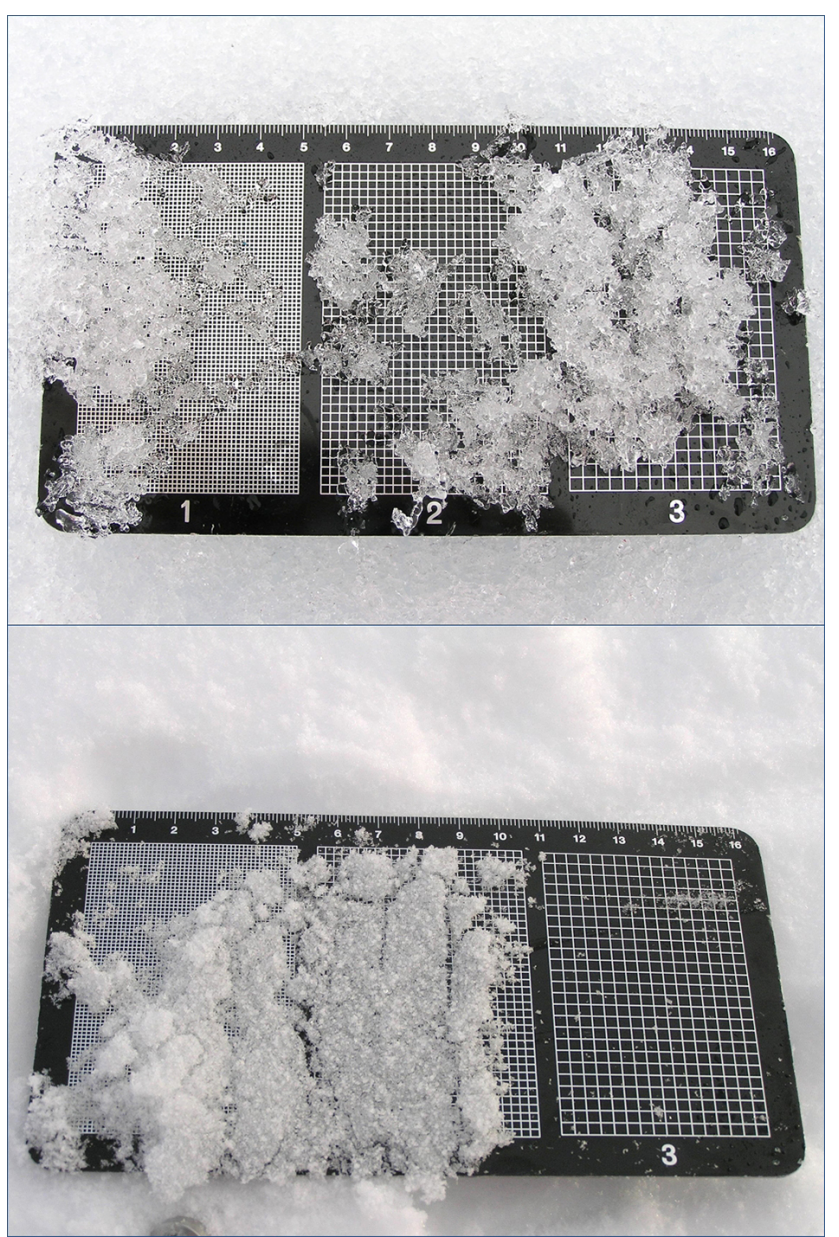

Figure 1. Typical grains of white ice (top panel) and fresh snow (bottom panel) observed in the central Arctic during ARK XXVII/3 in 2012. The size of the underlying grid is 1,2 , and $3 \mathrm{~mm}$, respectively.

reflection of white ice and snow is to interpret them as consisting of independent spherical scatterers, the Mie solution being often used to calculate the IOPs (Bohren and Barkstrom, 1974; Choudhury and Chang, 1979; Wiscombe and Warren, 1980; Warren, 1982; Grenfell et al., 1994; Light et al., 1998; Grenfell and Warren, 1999; Hamre et al., 2004). However, a set of spherical scatterers, even polydispersed, has a number of typical scattering features, such as a minimum at the scattering angle of about $100^{\circ}$, a rainbow, or a glory. Neither white ice nor snow demonstrate these scattering features, so the Henyey-Greenstein scattering function is often used instead of the Mie one in the radiative transfer simulations (Light et al., 1998; Grenfell and Warren, 1999; Aoki et al., 2000; Hamre et al., 2004). At the same time, both optical and microphysical measurements show that the ice grains in snow and in the granular layer of white ice are really far from spheres and, in fact, irregularly shaped (Massom et al., 2001; Kokhanovsky et al., 2005; Matzl and Schneebeli, 2006; Kerbrat et al., 2008; Domine et al., 2008; Picard et al.,

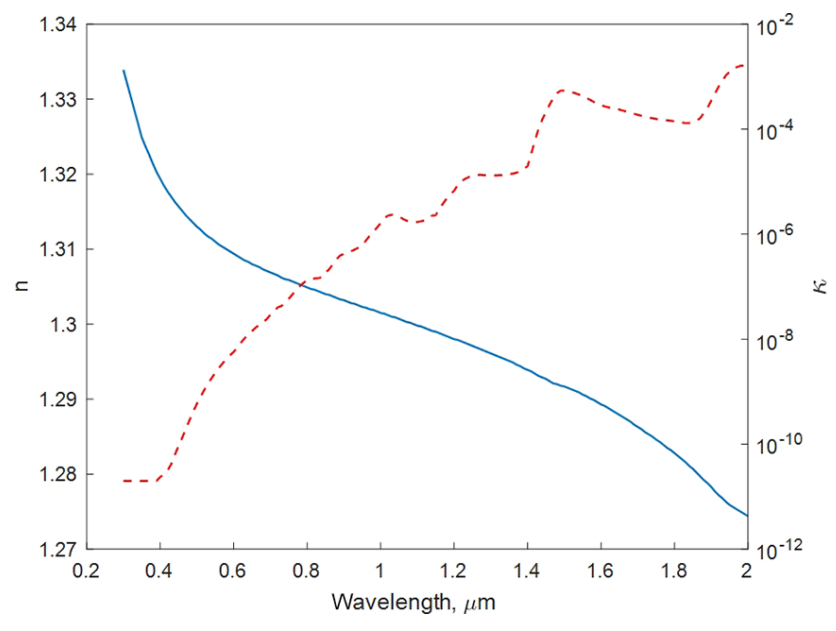

Figure 2. The refractive index of ice after Warren and Brand (2008): real part (left axis, solid curve) and imaginary part (right axis, dashed curve).

2009). Kokhanovsky and Zege (2004) developed the model of light scattering in snow that just posits the fact that the grain size is much larger than the wavelength and that the imaginary part of the refractive index is small. This model matches the case of white ice because the substance is the same (ice) and the typical grain size is even larger. Although the model was successfully used in many applications, e.g., in the retrieval of the snow grain size from satellite observations (Zege et al., 2011; Wiebe et al., 2013), there is still some dissatisfaction caused by the phenomenological nature of the model. The more consistent way is to consider snow (and hence white ice) as a porous material and to apply the model of a random mixture based on the stereological approach (Malinka, 2014). This approach uses the concept of the chord length distribution rather than the characteristics of a separate particle, and only requires that the mixture is stochastic. The mean chord length equals the mean photon path length inside one of the components of the mixture, and plays the role of the effective size of a grain or a gap. In addition to the requirements of stochasticity, the model of a random mixture (Malinka, 2014) uses the laws of geometrical optics. It is appropriate to recall that geometrical optics is applicable if the characteristic obstacle size is much larger than the wavelength, the real part of the refractive index differs significantly from unity, and its imaginary part is small. A typical grain of fresh snow is about $100 \mu \mathrm{m}$ (and grows with age) and, as it was mentioned above, a granule in white ice is on the order of millimeters, which is evidently much larger than the wavelength of visible and infrared (IR) light. The spectral behavior of the complex refractive index of ice according to Warren and Brandt (2008) is shown in Fig. 2.

As it is seen from Fig. 2, the refractive index of ice meets the above-mentioned requirements in the wavelength range of $0.3-2 \mu \mathrm{m}$. 


\subsection{Microphysical characteristics}

Most microphysical characteristics of the random mixture can be expressed in terms of the mean chords $a$ and $h$ that are the mean photon path length in ice and air gaps, respectively (Kendall and Moran, 1963; Pielou, 1964; Switzer, 1965; Gille, 2000; Gille et al., 2002). Thus, the volume fraction of ice $\beta$, the porosity $\phi$, the bulk density $\rho$, and the ice density $\rho_{\text {ice }}$ are related by

$\beta=1-\phi=\frac{\rho}{\rho_{\text {ice }}}=\frac{a}{a+h}$.

The autocorrelation length $l_{\mathrm{c}}$ is

$l_{\mathrm{c}}=\frac{a h}{a+h}$.

The specific area $s$ of the ice-air interface per unit volume of the mixture is

$s=\frac{4 \phi(1-\phi)}{l_{\mathrm{c}}}=\frac{4}{a+h}$.

The specific surface area (SSA) per sample mass equals

$\mathrm{SSA}=\frac{s}{\rho}=\frac{4}{(a+h) \rho_{\text {ice }} \beta}=\frac{4}{\rho_{\text {ice }} a}$.

Relationship (Eq. 4) is valid not only for the model of a porous material, but also for an ensemble of randomly oriented convex particles, which is a limit case of a random mixture. In that case the mean chord $a$ is inversely related to the commonly used surface-area-to-volume ratio $\langle S\rangle /\langle V\rangle$ :

$a=\frac{4\langle V\rangle}{\langle S\rangle}=\frac{\langle V\rangle}{\left\langle S_{\perp}\right\rangle}$,

where $S_{\perp}$ is the particle projection area, and the symbol 〈〉 denotes ensemble averaging.

Equation (5) indicates that the mean chord in the ensemble of particles coincides (to an accuracy of the factor of $3 / 2$ or $3 / 4$, depending on whether either radius or diameter of the equivalent sphere is used by the different authors) with the standard definitions of the effective size of irregular grains in snow (Kokhanovsky and Zege, 2004; Domine et al., 2008; Zege et al., 2008; Picard et al., 2009) and the effective radius of polydispersed spherical droplets in aerosols and clouds (Dobbins and Jizmagian, 1966; Naumenko, 1971; Hansen and Travis, 1974). However, Eq. (4) is more general, as the model of the stochastic mixture does not include the requirement of grain convexity, and can be applied to a densepacked medium.

\subsection{Light scattering characteristics}

The optical properties of the random mixture are determined by the spectral behavior of the complex refractive index $m+i \kappa$ and the mean chords $a$ and $h$. The main light scattering characteristics used in the radiative transfer theory are the extinction coefficient $\varepsilon$, the photon survival probability (single scattering albedo) $\omega_{0}$, and the scattering phase function $p(\theta)$. For the random mixture that has the exponential chord length distribution and to which the laws of geometrical optics are applicable, these values have been derived in Malinka (2014) and are given in Eqs. (6)-(16).

The extinction coefficient and the single scattering albedo are equal to

$\varepsilon=\frac{1}{a+h}$,

$\omega_{0}=1-\frac{x T_{\mathrm{diff}}}{x+T_{\mathrm{diff}}}$,

with

$x=\alpha n^{2} a$,

where $\alpha$ is the absorption coefficient of ice:

$\alpha=\frac{4 \pi}{\lambda} \kappa$,

and $T_{\text {diff }}$ is the Fresnel transmittance of diffuse light through the air-ice boundary:

$$
\begin{aligned}
T_{\text {diff }}= & \frac{2\left(5 n^{6}+8 n^{5}+6 n^{4}-5 n^{3}-n-1\right)}{3\left(n^{3}+n^{2}+n+1\right)\left(n^{4}-1\right)} \\
& +\frac{n^{2}\left(n^{2}-1\right)^{2}}{\left(n^{2}+1\right)^{3}} \ln \frac{n+1}{n-1}-\frac{8 n^{4}\left(n^{4}+1\right)}{\left(n^{4}-1\right)^{2}\left(n^{2}+1\right)} \ln n .
\end{aligned}
$$

In the spectral range $0.3-1.1 \mu \mathrm{m}$ (the range we will consider hereinafter) the real part $n$ of the refractive index of ice changes in the range $1.300-1.334$; the value $1-T_{\text {diff }}$ changes in the interval $6.11 \times 10^{-2} \div 6.95 \times 10^{-2}$

The expression for the phase function is a little bit more complex. It is presented as a series in the Legendre polynomials $P_{l}(x)$ :

$p(\theta)=\frac{1}{\omega_{0}}\left[R_{\text {out }}\left(\theta_{\mathrm{i}}\right)+\frac{1}{n^{2}} \sum_{l=0}^{\infty}(2 l+1) \frac{t_{l}^{2}}{1+\alpha a-r_{l}^{\text {in }}} P_{l}(\cos \theta)\right]$.

Here, $R_{\text {out }}\left(\theta_{\mathrm{i}}\right)$ is the Fresnel reflectance of the air-ice interface for incident angle $\theta_{i} ; t_{l}$ and $r_{l}^{\text {in }}$ are the coefficients of expansion of the functions $F_{\mathrm{t}}(\theta)$ and $F_{\mathrm{in}}(\theta)$ in the Legendre polynomials:

$F_{\mathrm{t}}(\theta)=\sum_{l=0}^{\infty} \frac{2 l+1}{4 \pi} t_{l} P_{l}(\cos \theta), F_{\mathrm{in}}(\theta)=\sum_{l=0}^{\infty} \frac{2 l+1}{4 \pi} r_{l}^{\text {in }} P_{l}(\cos \theta)$,

where the functions $F_{\mathrm{t}}(\theta)$ and $F_{\text {in }}(\theta)$ describe the angular distribution of light, transmitted and internally reflected by the air-ice interface, respectively: 


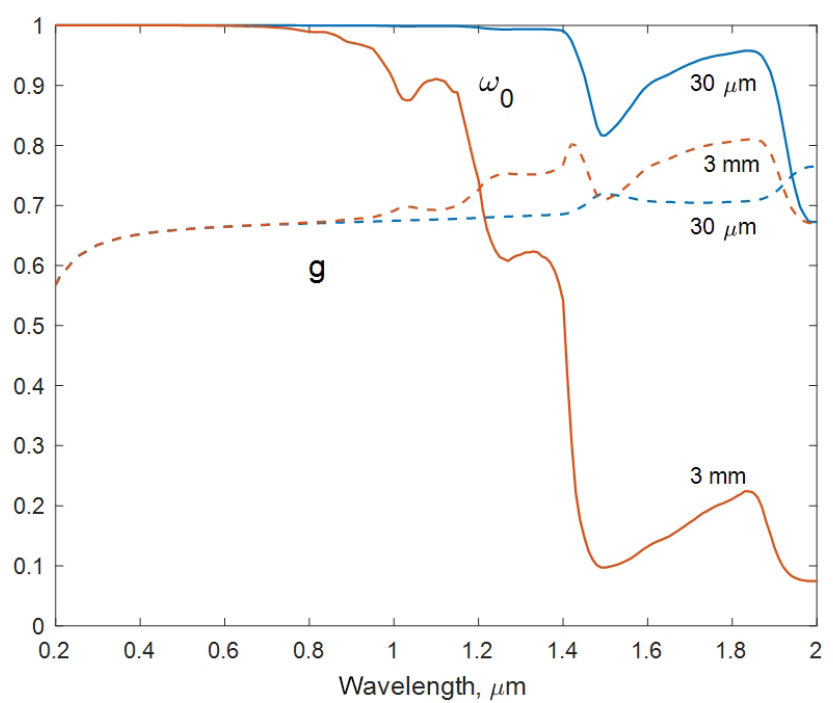

Figure 3. Spectral dependence of the photon survival probability (solid) and the average cosine (dashed) for the random ice-air mixture with a mean chord of $30 \mu \mathrm{m}$ (blue) and $3 \mathrm{~mm}$ (red).

$F_{\mathrm{t}}(\theta)= \begin{cases}T_{\text {out }}\left(\theta_{\mathrm{i}}\right) \frac{n^{2}(n \cos \theta-1)(n-\cos \theta)}{\pi\left(n^{2}-2 n \cos \theta+1\right)^{2}}, & \cos \theta>1 / n \\ 0, & \cos \theta<1 / n\end{cases}$

$F_{\text {in }}(\theta)=\frac{R_{\text {in }}\left(\theta_{\text {in }}\right)}{4 \pi}$,

where $T_{\text {out }}\left(\theta_{\mathrm{i}}\right)$ and $R_{\text {in }}\left(\theta_{\text {in }}\right)$ are the Fresnel transmittance at incidence angle $\theta_{\mathrm{i}}$ and the internal reflectance at incidence angle $\theta_{\text {in }}$. Angles $\theta, \theta_{\mathrm{i}}$, and $\theta_{\text {in }}$ are related by

$\theta=\theta_{\mathrm{i}}-\arcsin \frac{\sin \theta_{\mathrm{i}}}{n}, \quad \theta_{\mathrm{in}}=\frac{\pi-\theta}{2}$.

From Eqs. (11)-(14) it is possible to derive the analytical expression for the average cosine $g$ of the phase function:

$$
\begin{aligned}
g & =\langle\cos \theta\rangle=\frac{1}{2} \int_{0}^{\pi} p(\theta) \cos \theta \sin \theta d \theta \\
& =\frac{1}{\omega_{0}}\left(r_{1}+\frac{n^{2} t_{1}^{2}}{T_{\text {diff }}\left(1-n^{2}\right)-r_{1}+n^{4}(1+\alpha a)}\right),
\end{aligned}
$$

where

$$
\begin{aligned}
r_{1}= & \frac{n\left(3 n^{11}+3 n^{10}+25 n^{9}+25 n^{8}+22 n^{7}-282 n^{6}+138 n^{5}+186 n^{4}+151 n^{3}-89 n^{2}+13 n-3\right)}{24(n+1)\left(n^{4}-1\right)\left(n^{2}+1\right)^{2}} \\
& +\frac{8 n^{4}\left(n^{6}-3 n^{4}+n^{2}-1\right)}{\left(n^{4}-1\right)^{2}\left(n^{2}+1\right)^{2}} \ln n-\frac{\left(n^{8}+12 n^{6}+54 n^{4}-4 n^{2}+1\right)\left(n^{2}-1\right)^{2}}{16\left(n^{2}+1\right)^{4}} \ln \frac{n+1}{n-1}, \\
t_{1} & =\frac{3 n^{8}+3 n^{7}-17 n^{6}+55 n^{5}-39 n^{4}-7 n^{3}-27 n^{2}-11 n-8}{24(n+1)\left(n^{4}-1\right) n} \\
& -\frac{\left(n^{2}-1\right)^{4}}{16\left(n^{2}+1\right)^{2} n} \ln \frac{n+1}{n-1}+\frac{4 n^{5}}{\left(n^{4}-1\right)^{2}} \ln n
\end{aligned}
$$

The examples of the spectral dependence of the photon survival probability $\omega_{0}$ and the average cosine $g$ for the random

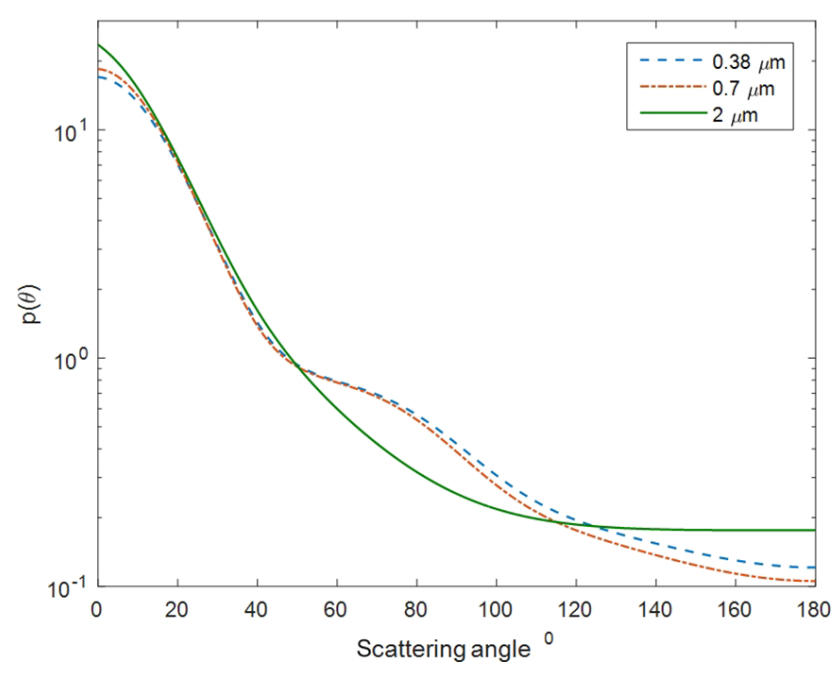

Figure 4. Simulated phase functions of the random ice-air mixture with the mean chord of $2 \mathrm{~mm}$ for different wavelengths.

ice-air mixtures with $a=30 \mathrm{~mm}$ (fresh fine snow grains) and $a=3 \mathrm{~mm}$ (aged white ice) are shown in Fig. 3. It is seen that the medium is practically nonabsorbing in the visible and near-IR range (the photon arrival probability is greater than 0.85 in the interval $0.3-1.1 \mu \mathrm{m}$ ), which justifies the name of "white ice". The average cosine $g$ takes the values from 0.63 at $0.3 \mu \mathrm{m}$ to 0.69 at $1.1 \mu \mathrm{m}$, with a mean value of about 0.67 . Note that this value refers to the geometrical optics being applied to the random mixture. When considering a separate particle, the total average cosine (geometrical optics + diffraction) will approximately be $(g+1) / 2$, i.e., $\sim 0.84$.

The phase functions of the mixture with $a=2 \mathrm{~mm}$ at different wavelengths are shown in Fig. 4. The wavelengths are chosen to be at the edges of the visible range (380 and $700 \mathrm{~nm})$ and in the shortwave infrared (SWIR) range $(2 \mu \mathrm{m})$. The phase functions are similar in the forward scattering region for all the wavelengths, and are practically independent of wavelength in the visible range.

\subsection{Absorption}

The spectral absorption of the random mixture is mainly determined by the imaginary part of the refractive index (see Eqs. 7-9). In the case of ice it has a pronounced minimum at about $0.3-0.4 \mu \mathrm{m}$ (see Fig. 2). However, the spectral behavior of white ice reflectance measured in situ shows the decrease in the blue range in many cases (see e.g. Figs. 8 and 11). This effect can be explained by the measurement geometry, when light from the sky and direct sunlight are added in different proportions at different wavelengths (see Sect. 4.2). However, careful analysis of the albedo field measurements, as well as the satellite data, shows that this effect is not sufficient to explain this spectral behavior. This means the presence of some absorbing contaminant. 
There can be different contaminants in ice. The particles of sediments from the atmosphere, which could be both longdistance-transferred (as with Sahara dust) or local (pollution from industrial centers), can affect the sea ice albedo drastically (see e.g., Light et al., 1998; Marks and King, 2014; Lamare et al., 2016). For example, clay, slit, and sand particles are found in the ice situated far from a coastline in the Beaufort Sea (Reimnitz et al., 1993) and in the central Arctic (Nürnberg et al., 1994). However, from our perspective, the yellow substance - dissolved organic matter (DOM) from seawater - is ideally suited to the role of ice contaminant absorbing in the blue region. The spectrum of the yellow substance (Bricaud et al., 1981) with the corrections done by Kopelevich et al. (1989) is

$\alpha_{y}(\lambda)= \begin{cases}\alpha_{y}(390) \exp [-0.015(\lambda-390)], & \lambda \leq 500, \\ \alpha_{y}(390) \exp [-0.015(500-390)-0.011(\lambda-500)], & \lambda>500,\end{cases}$

where $\lambda$ is in nanometers and $\alpha_{y}(390)$ is the only free parameter that determines the spectrum.

Here the concentration of DOM is represented implicitly through its absorption coefficient $\alpha_{y}(\lambda)$ at $\lambda=390 \mathrm{~nm}$. This is a conventional way to describe the DOM absorption used in the ocean optics (see e.g., the fundamental monograph of Mobley, 1994).

To take the absorption by the yellow substance in white ice into account, we rewrite Eq. (9) as

$\alpha=\frac{4 \pi}{\lambda} \kappa+\alpha_{y}$

The presence of the yellow substance in both Arctic and Antarctic ice was reported by many authors (Thomas et al., 1995, 2001; Bhatia et al., 2010; Norman et al., 2011; Beine et al., 2012; Grannas et al., 2014; Hansell and Carlson, 2014), and was sufficient to represent the shape of most of the reflection spectra we have analyzed. The specific choice of the yellow substance is only dictated by the albedo decrease in the blue range. As soon as the specific spectral features of other contaminants (Chl $a$ et al.) appear, their absorption spectra can be easily added to the right-hand part of Eq. (18).

\section{Reflectance of white ice}

The IOPs of the upper layer of white ice are defined in Sect. 2. The question that remains unanswered is the stratification of IOPs in the lower layers. The IOPs of ice change drastically with depth; however, the upper scattering layer is the main factor that determines the white ice reflection. The lower layers may only slightly affect the reflectance spectrum. Moreover, the upper part of an ice sheet, just below the scattering layer, contains a lot of air inclusions (about 4-5\%) (Gavrilo and Gaitskhoki, 1970; Mobley et al., 1998); thus its spectral behavior should be similar to that of the upper layer, which is a mixture of ice and air. Therefore, we describe the reflective properties of the whole ice sheet, considering just the scattering layer, but with effective parameters that can slightly differ from the real ones to take the effect of the lower layers into account.

\subsection{Asymptotic formulas}

Given the inherent optical properties of a layer, the apparent optical properties (AOPs) can be calculated with any appropriate radiative transfer code. However, keeping in mind further application of the developed model to an inverse problem, one would prefer to speed up the process of a solution to the direct problem. Analytical formulas are most suitable for this purpose. As white ice and snow are bright surfaces with high albedo, the asymptotic formulas of the radiative transfer theory that describe the behavior of AOPs of an optically thick layer with weak absorption (Rozenberg, 1963; Germogenova, 1963; Hulst, 1968; Sobolev, 1975; Zege et al., 1991) can be applied to this case.

Here we consider the following spectral AOPs: the BRF (bidirectional reflectance factor) $R$, the albedo at direct incidence $r\left(\theta_{0}\right)$, i.e., the directional-hemispherical reflectance, and the albedo at diffuse incidence $r_{\mathrm{d}}$, i.e., the bihemispherical reflectance. The BRF depends on the polar angles of incidence and observation ( $\theta_{0}$ and $\theta$, respectively) and the azimuth $\varphi$. All the AOPs are also spectrally dependent. We omit the variables $\theta, \theta_{0}, \varphi$, and $\lambda$ for brevity, where it does not cause misunderstanding.

The following approximate solution $R_{\infty}$ for the BRF of a semi-infinite layer is given by Zege et al. (1991):

$R_{\infty}=R_{\infty}^{0} e^{-Y}$,

where $R_{\infty}^{0}$ is the BRF of the semi-infinite layer with the same scattering phase function, but with no absorption (i.e., for $\left.\omega_{0}=1\right)$, and the exponential factor describes the effect of absorption:

$$
\begin{aligned}
& Y=y \frac{G(\theta) G\left(\theta_{0}\right)}{R_{\infty}^{0}}, \\
& G(\theta)=\frac{3}{7}(1+2 \cos \theta), \\
& y=4 \sqrt{\frac{\left(1-\omega_{0}\right)}{3\left(1-\omega_{0} g\right)}},
\end{aligned}
$$

where $\omega_{0}$ and $g$ are, as usual, the single scattering albedo and the mean cosine of the scattering phase function.

For the albedos at direct and diffuse incidence Zege et al. (1991) suggest the appropriate formulas:

$r\left(\theta_{0}\right)=\exp \left(-y G\left(\theta_{0}\right)\right)$,
$r_{\mathrm{d}}=e^{-y}$.

The traditional asymptotic formulas of the radiative transfer theory for weak absorption are restricted by the first term of the expansion in the small parameter $y$ (Sobolev, 1975): 
$R_{\infty}=R_{\infty}^{0}-y G(\theta) G\left(\theta_{0}\right)$,

$r\left(\theta_{0}\right)=1-y G\left(\theta_{0}\right)$,

$r_{\mathrm{d}}=1-y$.

However, the wider range of the absorption values is required for spectroscopy of scattering media for many problems as in remote sensing of ice and snow. Equations (19)-(21) are converted to the strict asymptotic ones (Eq. 22) at small absorption $(y \ll 1)$, but they have a wider range of applicability because they regard the terms up to the third-order of $y$ (Rozenberg, 1963).

Equations (19)-(21) were successfully used in remote sensing of snow (Zege et al., 2011; Wiebe et al., 2013). Their efficiency is caused by the fact that the albedo of snow cover is very high (up to $\sim 1$ in the blue-green range), so that a layer with a thickness of a few tens of centimeters can be considered as optically infinite. Unlike snow cover, white ice has an albedo of about 0.7-0.8 (or even less) in the blue-green region, which means that its optical thickness $\tau$ is finite. As a consequence, the optical thickness $\tau$ is the main parameter that determines its reflection and transmission.

The transition from the infinite to the large but finite optical depth $\tau$ can be made in the case of weak absorption by the asymptotic formula (Germogenova, 1963; Hulst, 1968):

$R=R_{\infty}-2 \frac{y G(\theta) G\left(\theta_{0}\right)}{e^{2 Z}-1}$,

where

$Z=\gamma \tau+y$,

and $\gamma$ is the asymptotic attenuation coefficient:

$\gamma=\sqrt{3\left(1-\omega_{0}\right)\left(1-\omega_{0} g\right)}$.

Using Eqs. (19) and (20), for Eq. (23) we get

$R=R_{\infty}^{0} e^{-Y}-2 \frac{y G(\theta) G\left(\theta_{0}\right)}{e^{2 Z}-1}=R_{\infty}^{0}\left(e^{-Y}-2 \frac{Y}{e^{2 Z}-1}\right)$.

In order to extend the scope of applicability of Eq. (26), we proceed in the spirit of Rozenberg (1963) and replace the linear term $Y$ by the hyperbolic term $\sinh Y$ :

$$
\begin{aligned}
R & =R_{\infty}^{0}\left(e^{-Y}-2 \frac{\sinh Y}{e^{2 Z}-1}\right)=R_{\infty}^{0}\left(e^{-Y}-\frac{e^{Y}-e^{-Y}}{e^{2 Z}-1}\right) \\
& =R_{\infty}^{0} \frac{e^{-Y+2 Z}-e^{-Y}-e^{Y}+e^{-Y}}{e^{2 Z}-1}=R_{\infty}^{0} \frac{e^{-Y+2 Z}-e^{Y}}{e^{2 Z}-1} \\
& =R_{\infty}^{0} \frac{\sinh (Z-Y)}{\sinh Z}
\end{aligned}
$$

Finally,

$R=R_{\infty}^{0} \frac{\sinh \left(\gamma \tau+y\left[1-G(\theta) G\left(\theta_{0}\right) / R_{\infty}^{0}\right]\right)}{\sinh (\gamma \tau+y)}$.
For the albedos, analogously we have

$r\left(\theta_{0}\right)=\frac{\sinh \left(\gamma \tau+y\left[1-G\left(\theta_{0}\right)\right]\right)}{\sinh (\gamma \tau+y)}$,

$r_{\mathrm{d}}=\frac{\sinh \gamma \tau}{\sinh (\gamma \tau+y)}$.

Equation (29) coincides with the formulas given in Zege et al. (1991). Equations (28)-(29) turn into Eqs. (19) and (21) for the semi-infinite layer at $\tau \rightarrow \infty$.

\subsection{Numerical verification}

Equation (28) was verified numerically with the radiative transfer code RAY (Tynes et al., 2001). Figures 5-6 present the BRF of white ice with $\tau=8.5$ and $a=3.333 \mathrm{~mm}$ at the wavelength of $490 \mathrm{~nm}$ (no absorption) and $885 \mathrm{~nm}$ (significant absorption).

For the case of significant absorption, the error of Eq. (28) is not greater than $5 \%$ if either $\theta$ or $\theta_{0}$ is less than $45^{\circ}$, and is not greater than $10 \%$ if both $\theta$ and $\theta_{0}$ are greater than $45^{\circ}$. For the nonabsorbing layer, the maximum error of Eq. (28) is $4 \%$ for both $\theta$ and $\theta_{0}$ equal to $0^{0}$.

Figure 7 presents the spectral albedo for the same layer. The error of the asymptotic Eq. (29) is not greater than $2.5 \%$ for direct incidence and is less than $1 \%$ for diffuse one.

Let us underline that Eqs. (28)-(29) are approximate. Their accuracy decreases with increasing absorption and with decreasing optical thickness. All in all, the brighter the layer, the higher the accuracy.

Whereas the use of analytical formulas speeds up calculations significantly, as compared to numerical methods, these formulas will be useful in problems where the calculation time is crucial, i.e., in iterative loops (see e.g., Zege et al., 2015).

\subsection{Model outline}

Let us summarize the above results. In the model presented, the BRF of the semi-infinite nonabsorbing layer $R_{\infty}^{0}$ and the mean cosine of the scattering phase function $g$ are determined by the phase function only, and do practically not depend on wavelength in the visible range (in fact, in the range $0.3-1.1 \mu \mathrm{m}$, where the photon survival probability $\omega_{0}$ is close to 1 ; see Fig. 3). Function $R_{\infty}^{0}$ is calculated only once with a radiative transfer code for different values of $\left(\theta, \theta_{0}, \varphi\right)$, and then used as a lookup table; the value of $g \approx 0.67$ (see Fig. 3 and a note in Sect. 2.2). The spectral dependence of reflectance is determined by the single scattering albedo $\omega_{0}$, which depends on the complex refractive index of ice $m$ and the effective grain size $a$. Absorption in the blue range can be affected by the adsorbed yellow substance (other possible pollutants are not taken into account, but can be easily included into the model). 
Table 1. Characteristics of white ice that determine its reflective properties.

\begin{tabular}{lll}
\hline Symbol & Characteristics & Comments \\
\hline$\tau$ & $\begin{array}{l}\text { Effective optical thickness of the } \\
\text { scattering layer }\end{array}$ & $\begin{array}{l}\text { Main value that determines reflection in total and the only value that } \\
\text { determines reflection in the range 500-550 nm, where absorption is } \\
\text { absent }\end{array}$ \\
\hline$a$ & $\begin{array}{l}\text { Effective grain size (the mean chord) } \\
\text { of the scattering layer (in } \mu \mathrm{m})\end{array}$ & $\begin{array}{l}\text { Together with the complex refractive index determines the spectral } \\
\text { behavior of the reflectance }\end{array}$ \\
\hline$\alpha_{y}(390)$ & $\begin{array}{l}\text { Absorption coefficient of the yellow } \\
\left.\text { substance at } 390 \mathrm{~nm}_{\text {in }} \mathrm{m}^{-1}\right)\end{array}$ & Responsible for absorption in the blue range \\
\hline
\end{tabular}
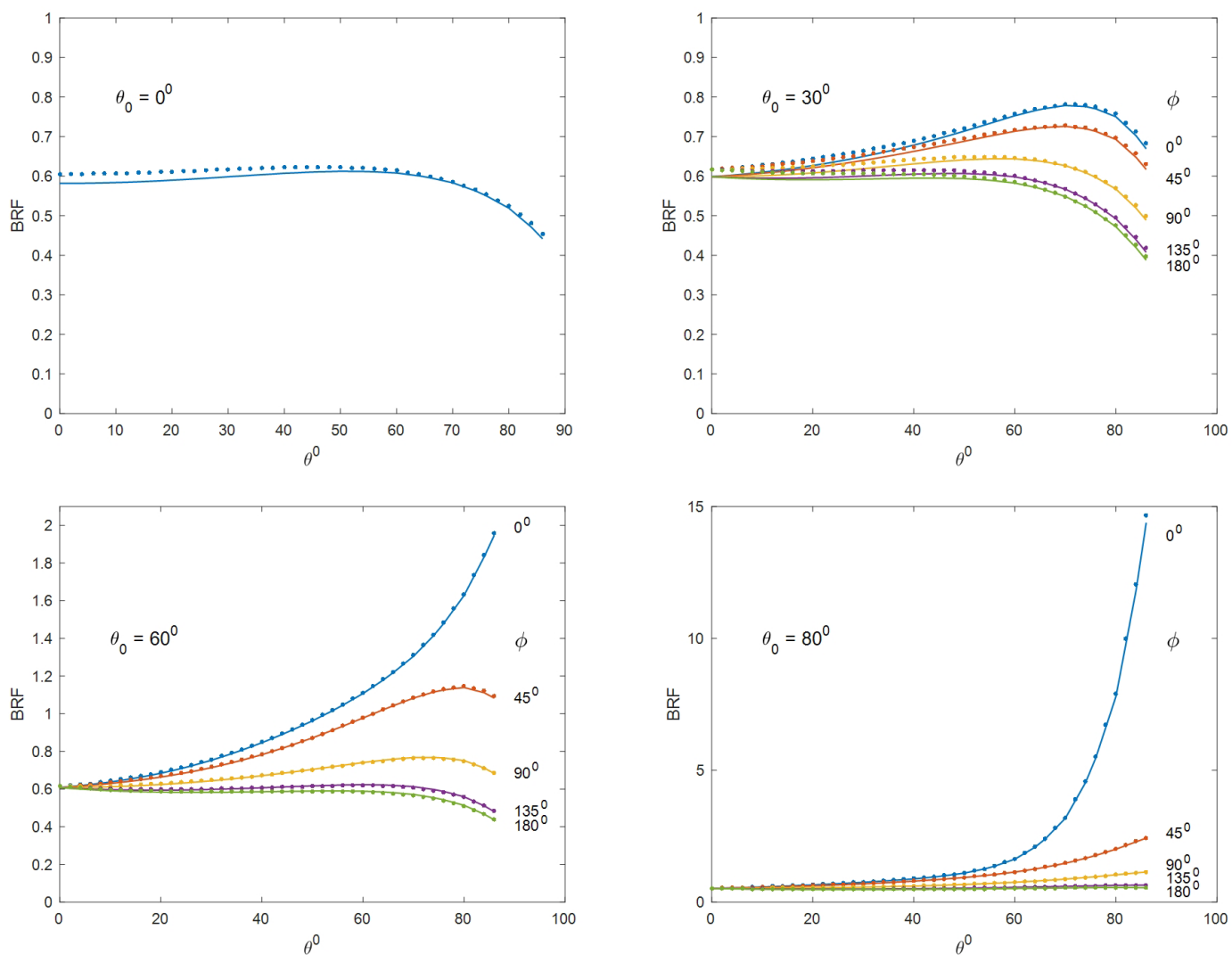

Figure 5. BRF of white ice with $\tau=8.5$ and $a=3.333 \mathrm{~mm}$ at $490 \mathrm{~nm}$, calculated with the RAY code (dots) and the asymptotic formula (curves).

Finally, the white ice reflective properties in the spectral range of $0.3-1.1 \mu \mathrm{m}$ are determined by only three independent parameters given in Table 1 .

These three values (together with the refractive index) completely determine the entire spectrum of all the reflective characteristics of white ice.

In the green range of the spectrum $(\sim 550 \mathrm{~nm})$, both ice and DOM absorptions are negligible. In the nonabsorbing case $\left(\omega_{0}=1, y=0, \gamma=0\right)$, with the value of $g \simeq 0.67$, Eqs. (28)-(29) turn into the limiting form:

$$
\begin{aligned}
& R=R_{\infty}^{0}-\frac{4 G(\theta) G\left(\theta_{0}\right)}{\tau+4}, \\
& r\left(\theta_{0}\right)=1-\frac{4 G\left(\theta_{0}\right)}{\tau+4}, \\
& r_{\mathrm{d}}=\frac{\tau}{\tau+4} .
\end{aligned}
$$

This form (Eq. 30) can be useful for the estimation of the optical thickness of white ice by the reflection at its spectral maximum at about $550 \mathrm{~nm}$. 

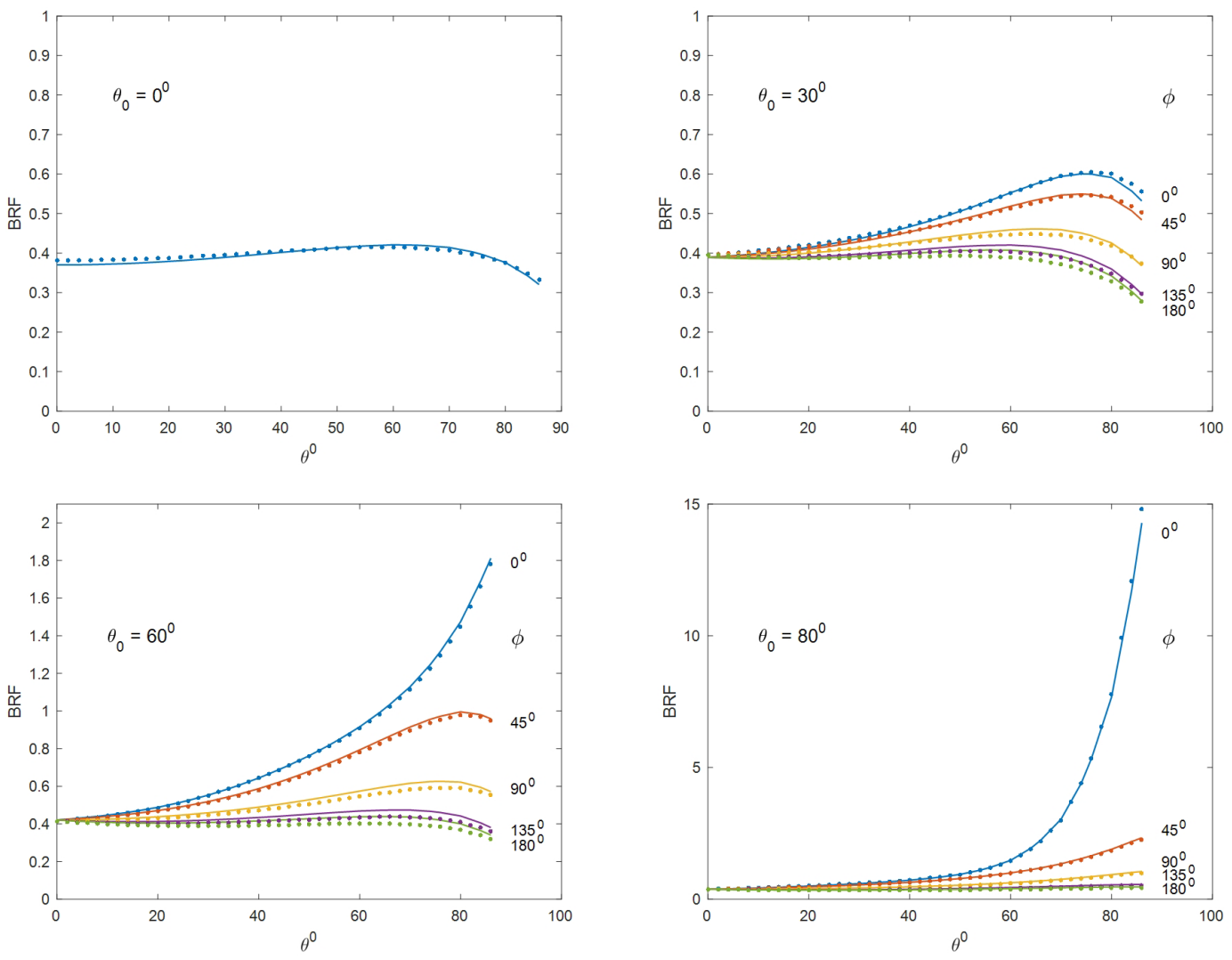

Figure 6. BRF of white ice with $\tau=8.5$ and $a=3.333 \mathrm{~mm}$ at $885 \mathrm{~nm}$, calculated with the RAY code (dots) and the asymptotic formula (curves).

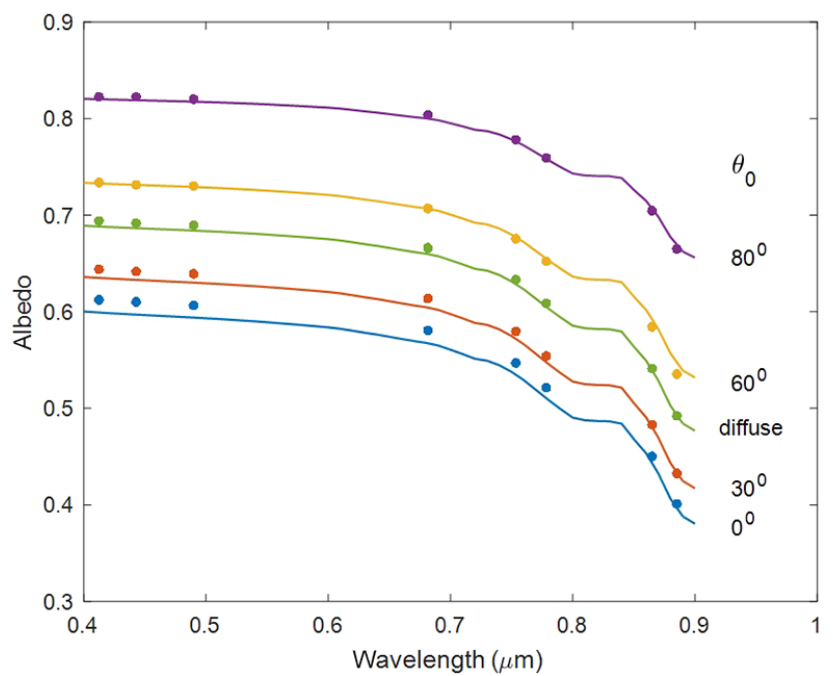

Figure 7. Spectral albedo of the same layer at different incidence (direct and diffuse), calculated with the RAY code (dots) and the asymptotic formulas (curves).

\section{Verification with the field data}

Now there are several questions to be answered, concerning the developed model.

1. How reliable is the model? How close are the theoretical spectra determined with only few parameters, shown in Table 1, to the measured spectra of white ice at different situations?

2. What is the scope of applicability of the model? Can it be applied to situations in which the surface differs from the standard white ice?

3. What are the statistics of the ice parameters? What is the range of their changes in reality?

The last question is very important for the regularization of the inverse problem (retrieving the ice properties from optical data). When a problem is mathematically incorrect and needs regularization, as in this case, it is very important to have some a priori information, e.g., the range of variation of the sought-for parameters, to exclude false solutions. 


\subsection{Albedo measurements}

The reflectance spectra of white ice were systematically measured for various melting ice situations during the R/V Polarstern cruise ARK-XXVII/3, 2 August-8 October 2012 (Istomina et al., 2016). The cruise track mainly followed the ice edge, and only in the second half of the cruise did the vessel enter thick multi-year ice. The thickness of the first-year ice at the edge varied from 0.5 to $2-3 \mathrm{~m}$ (single floes and ridges), with an average of around $1-1.5 \mathrm{~m}$ (the data stem from visual estimation of overturning crashed ice floes, done from the bridge of the vessel). During the cruise, a variety of field conditions could be observed, including clear and cloudy skies of various cloud coverage, melting, freezing, and snowfall events. The sea ice surface featured a variety of crystal sizes, from very fine fresh fallen snow to ice granules of about $2-3 \mathrm{~mm}$. The measurements were done during the ice stations, when the vessel was parked at the ice floe for several days. Altogether there were nine ice stations where the spectral albedo was measured (at any sky conditions). The measurements were always done around solar noon at the given longitude. The measurement run took $2-3 \mathrm{~h}$, during which the solar angle, cloud coverage, and surface conditions could change.

The portable spectroradiometer used for these measurements was the ASD FieldSpec Pro III, which uses three different sensors to obtain a spectrum from 350 to $2500 \mathrm{~nm}$ with the spectral resolution of $1.0 \mathrm{~nm}$. The optical fiber cable used as a sensor was aimed at a $10 \times 10 \mathrm{~cm}^{2}$ Spectralon white plate, which was directed towards the measured surface and then towards the sky. The ratio of these two measurements of the upwelling and downwelling radiances gives the albedo of the surface. The sensor was held horizontally on a $1 \mathrm{~m}$ long arm, facing perpendicular to the surface (a bullseye spirit level was used). The sensor was held above the surface at approximately $1 \mathrm{~m}$ height. The measurements were taken every $10 \mathrm{~m}$ along $200 \mathrm{~m}$ transect lines. A photograph of each measurement site was taken, and a short description of the surface was documented.

Low sun elevation is responsible for the increase of noise in the measured spectra, especially in the middle-IR part. Therefore only measurements from the first six ice stations in the visible and near-IR range $(0.35-1.35 \mu \mathrm{m})$ are used in this study. More details on the cruise can be found in Boetius et al. (2013).

\subsection{Measurements geometry and sky conditions}

The spectral albedo measurements at natural illumination can be affected by different factors, such as imperfect sky conditions, e.g., overcast sky, scattered cumulus clouds, and thin cirrus clouds in otherwise clear skies. In the case of scattered clouds, especially when a cumulus cloud could obscure the solar disk during the measurement process, the change of sky conditions would inevitably distort the measured quan- tity and lead to unreasonable values of albedo. Such spectra were filtered out manually.

The measurements were carried out from the end of August to the beginning of September. For the days of measurements at the six stations, the maximum solar elevation angles (at noon) were $21^{0}, 20^{\circ}, 19^{\circ}, 17^{0}, 15^{\circ}$, and $10^{\circ}$; i.e., the measurements were carried out at very low sun (zenith angle equals $90^{\circ}$ minus elevation angle). When the sun is low, the direct solar flux is comparable to the diffuse flux from the sky, making the measured albedo value be a mixture of those at direct and diffuse incidences. As the white ice albedo at direct incidence increases when the sun is approaching the horizon (see Eq. 30), for the low sun the albedo at direct incidence is greater than that at diffuse incidence (the zenith angle, at which they are equal, is approximately equal to $\arccos (2 / 3) \simeq 48^{0}$; see Eq. 30). It means that the light scattering by the sky makes the measured albedo lower than that at direct incidence. The greater the flux from the sky, the more essential this underestimation. In the clear sky the Rayleigh scattering is dominating and has strong spectral dependence, being significant in the blue and negligible in the red and IR range. This leads to the situation when the measured albedo values are closer to that at diffuse incidence in the blue range and to that at direct incidence in the red, producing the reflectance decrease in the blue, which can be mistaken for the presence of a contaminant. The situation becomes even more complicated when dealing with such a bright surface as white ice because of the essential multiple reflections between the surface and the atmosphere. To interpret the measurements' data correctly, we should examine this effect with more care.

Accurate documentation of atmospheric conditions in the field, including the atmosphere optical thickness, is needed in order to correct the field data, but is seldom available. On the Polarstern cruise, during the measurements, the following sky conditions were reported: completely overcast, overcast when the solar disk is visible, and clear sky with scattered thin cirrus clouds.

In complete overcast conditions, when the solar disk is completely hidden, the contribution of the direct solar light is equal to zero, and the incident illumination is completely due to the diffuse sky light, so the measured albedo is the bihemispherical reflectance $r_{\mathrm{d}}$.

Let us estimate the contribution of the direct light when the solar disk is visually observed through the clouds. Assuming that the direct light brightness $B_{0}$ is approximately constant across the solar disk, we can write in the case of overcast sky:

$B_{0}=\frac{E_{0} e^{-\tau_{\mathrm{cl}} / \cos \theta_{0}}}{\pi \gamma^{2}}$,

where $E_{0}$ is the extraterrestrial solar flux, $\tau_{\mathrm{cl}}$ is the optical thickness of the cloudy atmosphere $\left(e^{-\tau_{\mathrm{cl}} / \cos \theta_{0}}\right.$ is the attenuation factor), and $\pi \gamma^{2}$ is the solid angle of the solar disk $\left(2 \gamma \simeq 32^{\prime}\right)$. 
When the solar disk is visible, the sky brightness $B_{\mathrm{S}}$ is comparable in magnitude to the sun brightness:

$B_{\mathrm{s}} \sim B_{0}$.

At the same time, their fluxes are of different orders: the flux of the sky light is $\pi B_{\mathrm{s}}$, while the solar flux is $E_{0} \cos \theta_{0} e^{-\tau_{\mathrm{cl}} / \cos \theta_{0}}$. Taking Eq. (32) into account, we can say that the solar flux at the surface is less than the sky light flux by a factor of $\gamma^{-2} \sec \theta_{0}$, i.e., by more than $4.6 \times 10^{4}$ times. This means that in this case the measured albedo also corresponds to that at diffuse incidence $r_{\mathrm{d}}$.

Finally, the third case is the clear sky. Thin cirrus clouds may be present but visually, the sky is blue. The measured albedo corresponds to the value

$A=\frac{F_{\uparrow}}{F_{\downarrow}}$,

where $F_{\uparrow}$ and $F_{\downarrow}$ are up- and downwelling fluxes, respectively, which in this case can be approximately calculated by the following formulas (Malinka et al., 2016):

$$
\begin{aligned}
F_{\uparrow} & =\frac{R T}{1-r^{\mathrm{a}} r_{\mathrm{d}}}, \\
F_{\downarrow} & =T+\frac{r^{\mathrm{a}}}{1-r^{\mathrm{a}} r_{\mathrm{d}}} R T,
\end{aligned}
$$

where

$$
R T=t_{0} r\left(\theta_{0}\right)+t_{\mathrm{d}} \frac{1+6 r_{\mathrm{d}}}{7} .
$$

Here, as before, $r\left(\theta_{0}\right)$ and $r_{\mathrm{d}}$ are the surface albedos at direct and diffuse incidence, respectively, $T=t_{0}+t_{\mathrm{d}}$ is the atmospheric transmittance that is a sum of the direct solar light transmittance $t_{0}$ (attenuation factor) and the diffuse transmittance $t_{\mathrm{d}}$ that describes the scattering in the atmosphere and, thus, determines the sky brightness; $r^{\mathrm{a}}$ is the atmospheric albedo at diffuse incidence from below. (Eqs. 34-35 account for the multiple reflections between the surface and the atmosphere.)

Therefore, while processing the field data (see the next section), we interpret the measured value as the albedo at diffuse incidence in the cases of overcast and as given by Eqs. (33)-(35) for the clear sky. In the latter case the atmosphere model includes the molecular atmosphere (the Rayleigh scattering) with the Arctic background aerosol (Tomasi et al., 2007) and a thin cirrus cloud layer with an optical depth of 0.1 .

\subsection{Measured spectra retrieval}

Every spectrum consists of 1000 points of the measured values from 0.35 to $1.35 \mu \mathrm{m}$. These points were approximated with a curve, calculated by Eq. (29) (or Eq. 33 in appropriate cases) by fitting the three parameters from Table 1 (the best fit is understood in the least squares sense). Figures 8-12 present the comparison of the measured and retrieved albedo spectra. The respective retrieved ice parameters are presented in Table 2. A photo of the object of measurement is given for every plot. The measurement date and event number are shown (see Boetius and ARK-XXVII/3 Shipboard Scientific Party, 2012, for details), as well as the sky conditions.

Figure 8 represents the bright surfaces. The typical grain size in these cases varies from 400 to $800 \mu \mathrm{m}$. This is an intermediate case between the typical snow and the typical white ice. The surface could be treated as aged snow when snow grains become larger. These cases clearly demonstrate that there is no strict separation between snow and white ice. Note that the first two spectra are affected by the yellow substance (decrease in the blue range), while the third one represents the pure ice surface.

Figure 9 shows the typical white ice with the grain size of 1-4 mm, pure in the first two cases and with a little effect of the yellow substance in the third one. The discrepancies between measured and retrieved spectra at $\lambda>1.2 \mu \mathrm{m}$ hereinafter are explained by the error of approximate Eq. (29) for very low reflection.

Figure 10 presents the case of melt ice. The surface is dark and water-saturated. The layer is characterized by low values of optical thickness (5 and lower) and high values of the effective grain size (from $4 \mathrm{~mm}$ to $1 \mathrm{~cm}$ ). This case is important because it does not belong to the initial scope of the developed model, which is not presumed to describe wet snow or ice. Nevertheless, the spectra are retrieved satisfactorily, even when the spectral albedo maximum value is less than 0.4 .

Snow-covered surfaces are presented in Fig. 11. The optical thickness is high (30 and higher), and the grain size is about $100-300 \mu \mathrm{m}$, which is typical for fresh snow. The first spectrum is affected by a substantial amount of the yellow substance.

Overall, Figs. 8 to 11 demonstrate that snow and white ice can be described in the framework of a uniform approach.

In Fig. 12 some outstanding cases are presented. The first one is crusted snow, which has a similar spectrum to typical white ice and, as a consequence, is described by similar parameters. The second one is a snow-covered frozen pond. This case demonstrates that even a thin layer of snow has the same optical thickness as an ordinary layer of white ice $(\sim 9)$. The large value of the effective grain size $(\sim 10 \mathrm{~mm})$ does not match real snow grains, but rather it is responsible for high absorption in the IR by the homogeneous ice under the snow layer. Apparently the same situation takes place in the third case, a frozen ice crack. Bubbles in the upper ice layer produce a situation similar to the ice-air random mixture in the white ice scattering layer, but with a very large effective grain $(\sim 12 \mathrm{~mm})$. Visually, the crack looks dark, and its total optical thickness is low $(\sim 2)$.

In general, the analysis of the experimental data shows that the developed model describes the reflective properties of white ice and snow excellently, at least as regards the spectral albedo, and the cases that are beyond the initial framework of 

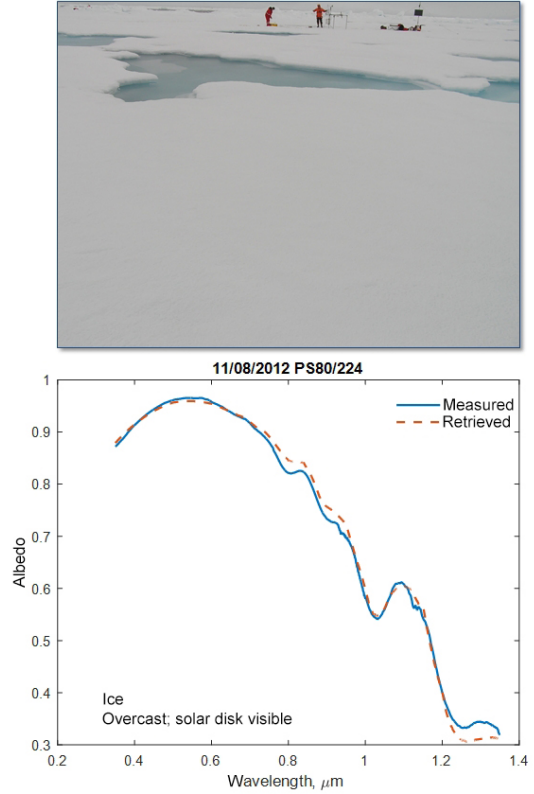
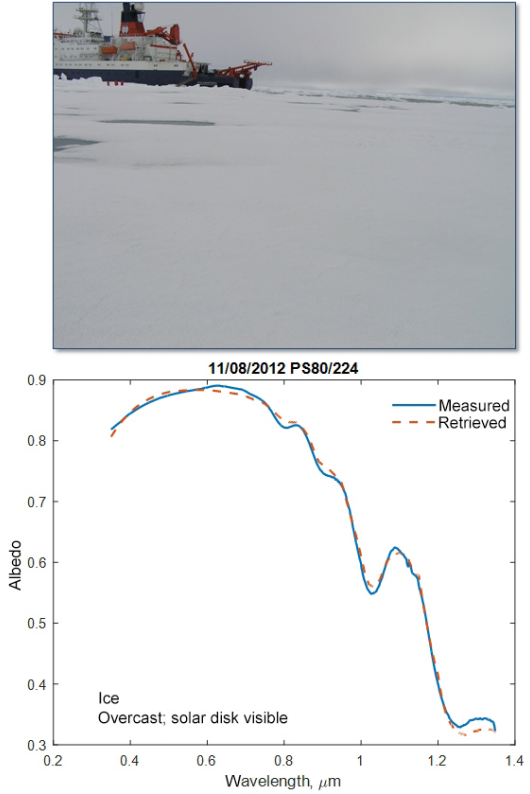
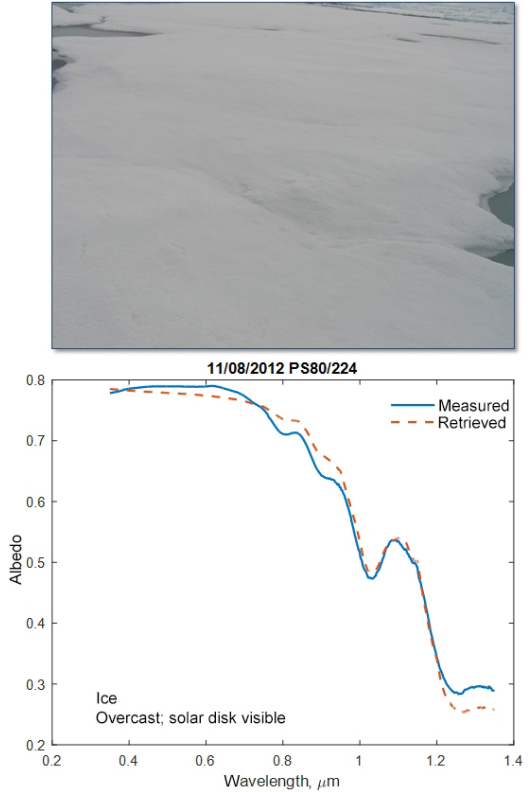

Figure 8. Bright white ice. The surface is dry; the scattering layer is $3-8 \mathrm{~cm}$ thick; the average air temperature is $-1.2^{\circ} \mathrm{C}$.
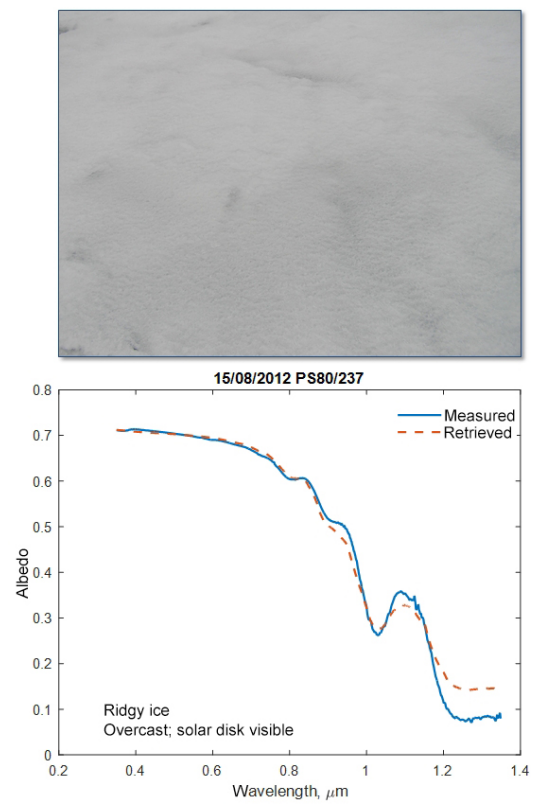
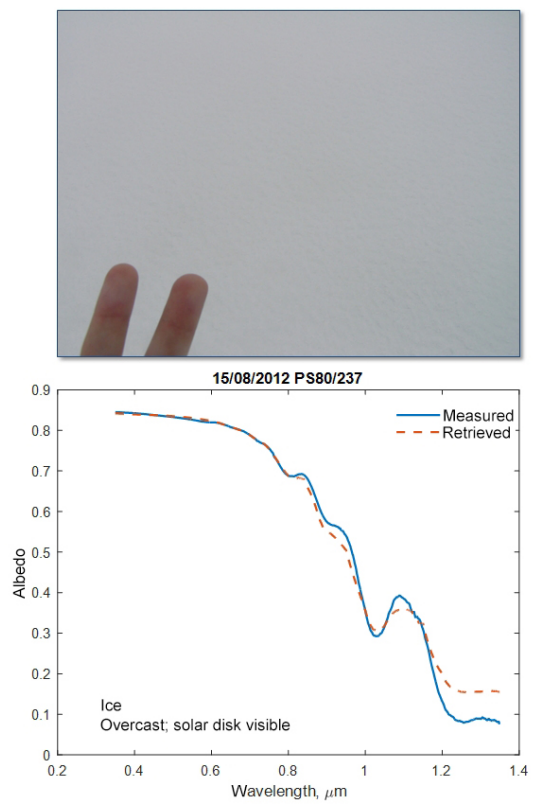
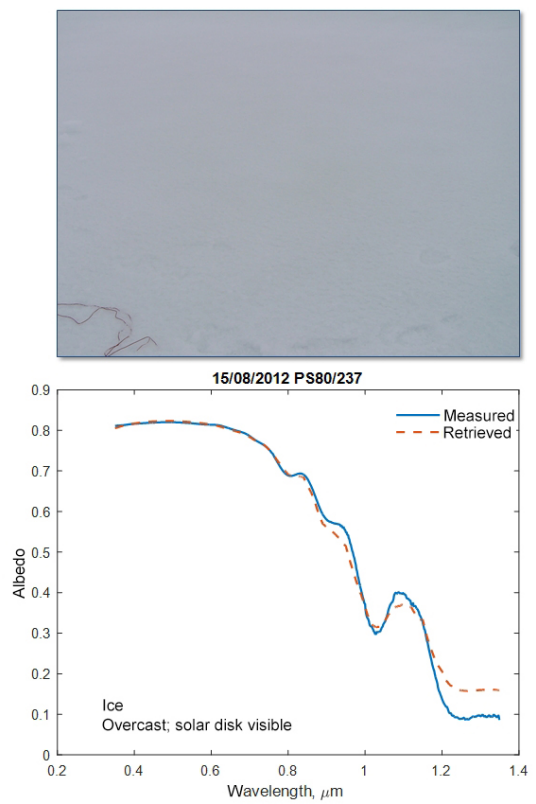

Figure 9. Typical white ice in Arctic summer. The surface is slightly wet; the grains are larger than those in dry white ice; the scattering layer is $12-18 \mathrm{~cm}$ thick. The average air temperature is $-1.1^{\circ} \mathrm{C}$.

the model such as wet ice/snow, crusted snow, frozen cracks, and snow-covered ponds quite satisfactorily.

\section{Conclusion}

This work presents the optical model of white ice, i.e., any kind of ice covered with the scattering layer that consists of ice grains mixed with air. The main characteristics that de- termine its optical, particularly reflective, properties are the optical thickness and the effective grain size (the mean chord of the ice component in the random ice-air mixture). The model only considers one pollutant, namely, the yellow substance that is responsible for absorption in the blue range. However, scattering and absorption by any sediment can be easily incorporated into the model described. 

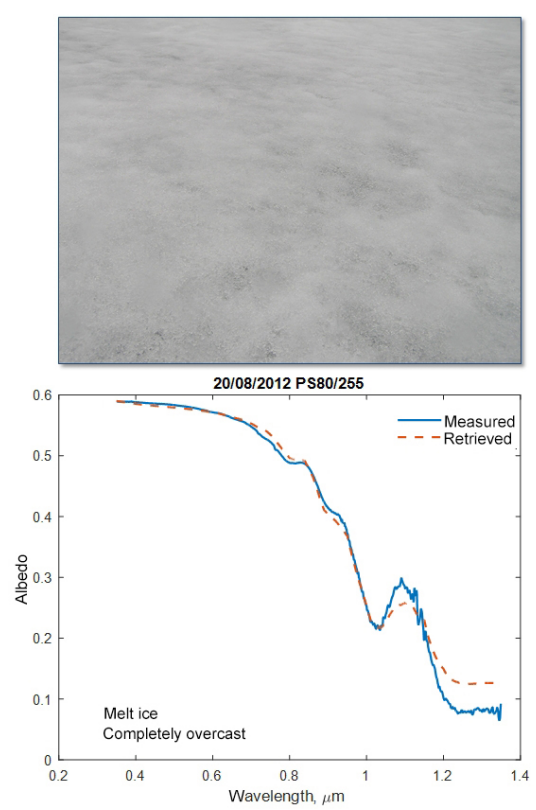
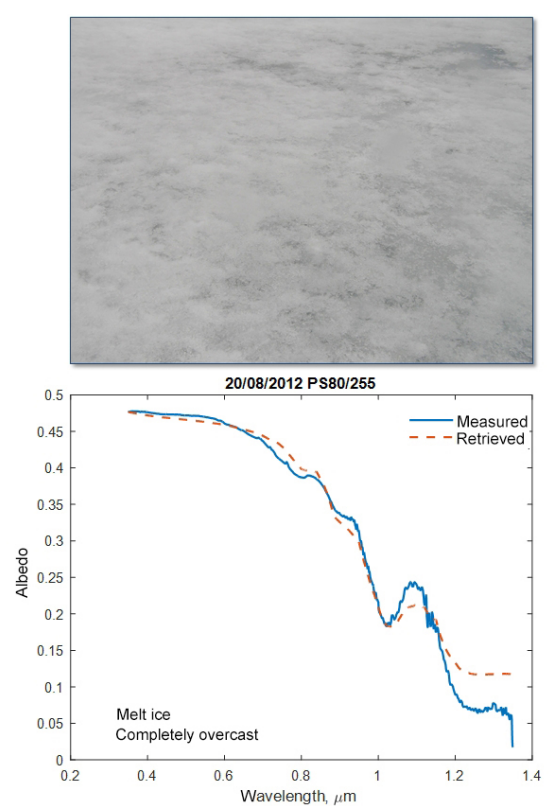
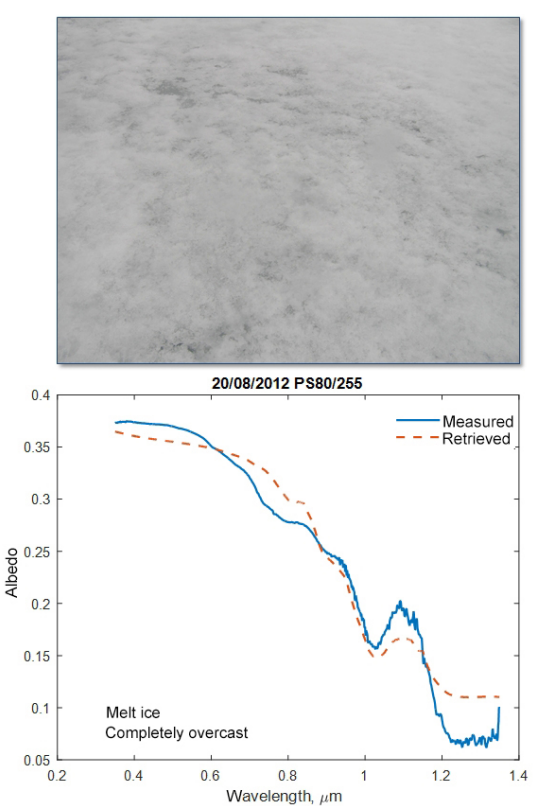

Figure 10. Melt ice. Melting (wet) scattering layer with depth of $1.5 \mathrm{~cm}$ (left panels) and $7 \mathrm{~cm}$ (the others). The degree of melting increases from left to right. The average air temperature is $+0.3^{\circ} \mathrm{C}$.
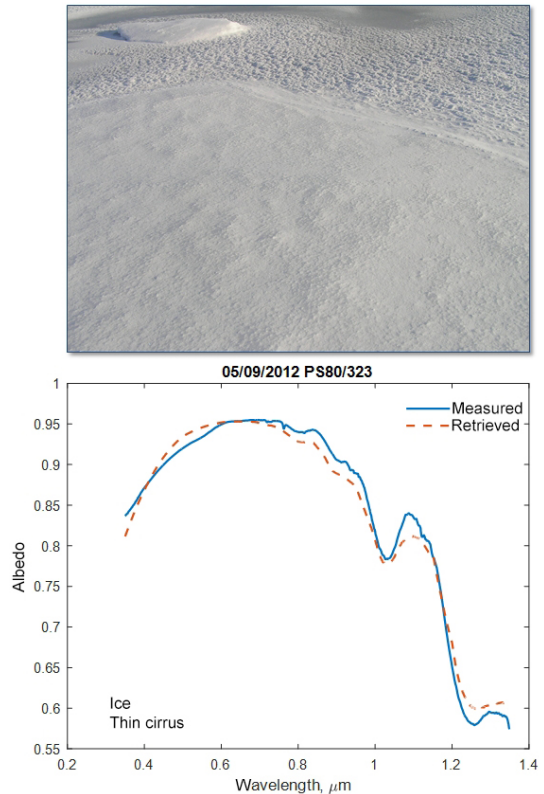
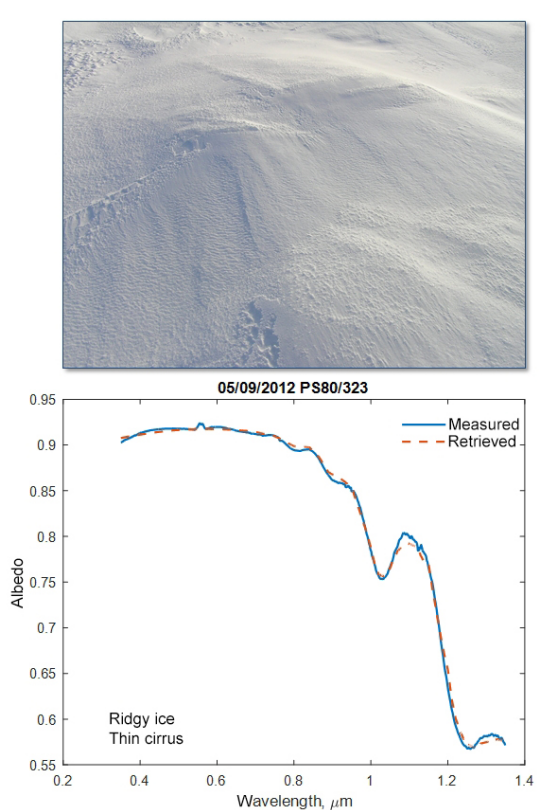
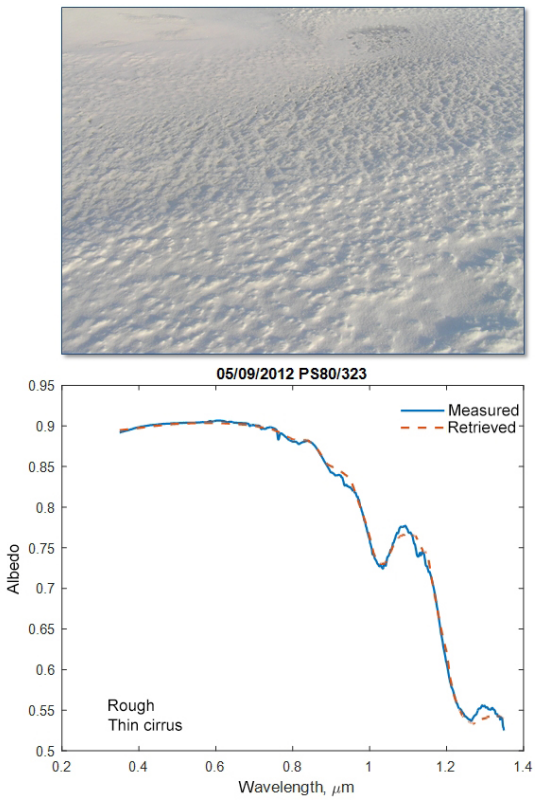

Figure 11. Snow-covered ice. The surface is fresh fallen fine-grained snow (up to $5 \mathrm{~cm}, 2.4 \mathrm{~cm}$ on average) on the wind-crusted older scattering layer $(2-4 \mathrm{~cm})$. The average air temperature is $-3.2^{\circ} \mathrm{C}$.

In addition, simple approximate formulas are put forward to calculate the BRF and albedo of a scattering layer of large but finite optical depth and low absorption, which is a case in point when dealing with white ice.

The verification with field data has shown that the model is sufficiently reliable: most of the measured spectra are retrieved with a high degree of accuracy by fitting only few pa- rameters. The initial model requirements are the following: the grain shapes should be close to random, their size should be much larger than the wavelength of light (beginning from about $10 \lambda$ ), and the layer should be quite bright, i.e. with the albedo higher than 0.5 in the visible, which means the optical depth is greater than 4 (see Eq. 30). However, the analysis has shown that the model works quite satisfactorily in the cases 

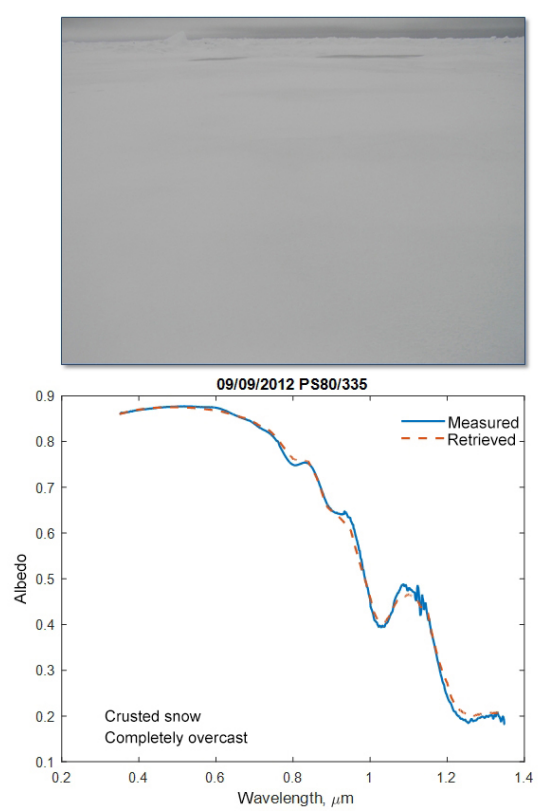
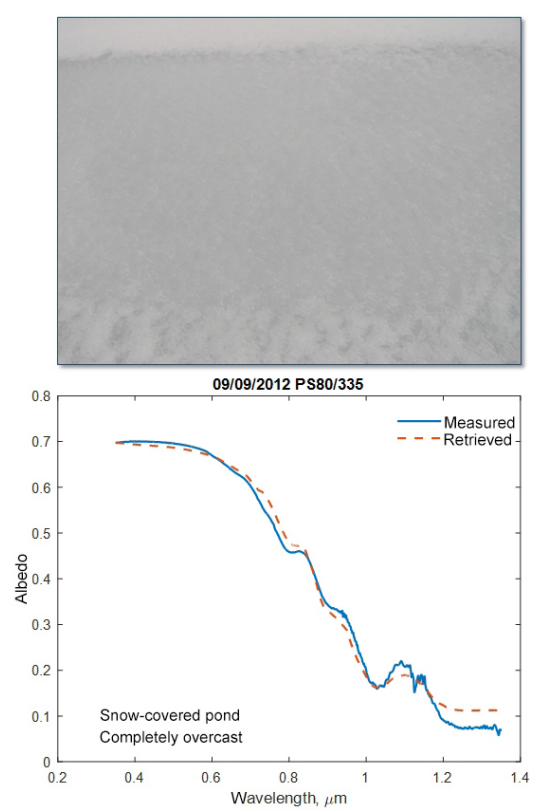
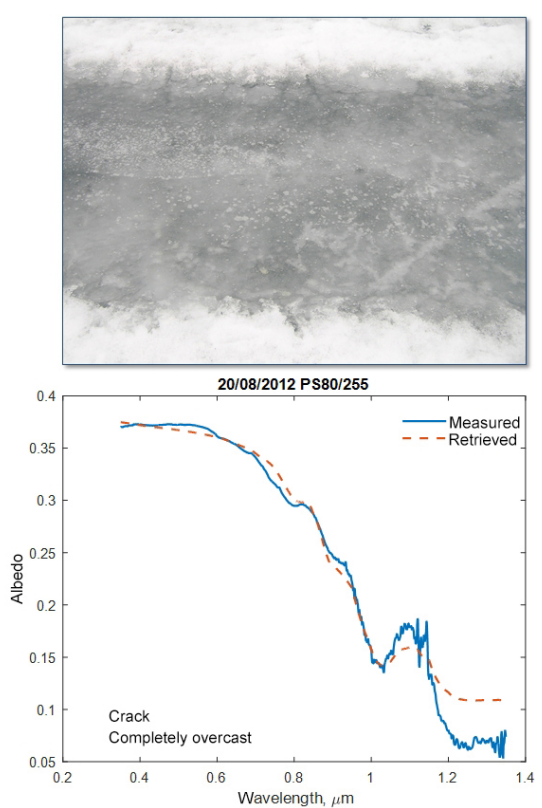

Figure 12. Three special cases: thin wind crust on top of fine fresh snow of $4 \mathrm{~cm}$ thickness (left panels), a frozen-over gray melt pond with snow on top (middle panels), and a frozen-over crack with air bubbles and algae inclusions (right panels). The average air temperature is $+0.3^{\circ} \mathrm{C}$ (right panels) and $-1.6^{\circ} \mathrm{C}$ (the others).

Table 2. Retrieved parameters of white ice. See Table 1 for explanation of parameters.

\begin{tabular}{llcccc}
\hline Figure & Type & Plot & $\tau$ & $a(\mu \mathrm{m})$ & $\alpha_{y}\left(\mathrm{~m}^{-1}\right)$ \\
\hline 8 & Bright white ice & 1 & $5.0 \times 10^{2}$ & $4.9 \times 10^{2}$ & $7.1 \times 10^{-1}$ \\
& & 2 & $3.2 \times 10^{1}$ & $4.5 \times 10^{2}$ & $2.0 \times 10^{0}$ \\
& & 3 & $1.4 \times 10^{1}$ & $7.2 \times 10^{2}$ & $2.9 \times 10^{-2}$ \\
\hline 9 & Typical white ice & 1 & $9.3 \times 10^{0}$ & $2.8 \times 10^{3}$ & $6.7 \times 10^{-4}$ \\
& & 2 & $2.0 \times 10^{1}$ & $2.3 \times 10^{3}$ & $2.2 \times 10^{-4}$ \\
& & 3 & $1.9 \times 10^{1}$ & $2.2 \times 10^{3}$ & $1.9 \times 10^{-1}$ \\
\hline \multirow{2}{*}{10} & Melting ice & 1 & $5.4 \times 10^{0}$ & $4.7 \times 10^{3}$ & $2.5 \times 10^{-4}$ \\
& & 2 & $3.4 \times 10^{0}$ & $6.7 \times 10^{3}$ & $6.0 \times 10^{-3}$ \\
& & 3 & $2.2 \times 10^{0}$ & $1.0 \times 10^{4}$ & $6.9 \times 10^{-3}$ \\
\hline \multirow{2}{*}{11} & Snow-covered ice & 1 & $7.3 \times 10^{1}$ & $1.7 \times 10^{2}$ & $7.4 \times 10^{0}$ \\
& & 2 & $3.2 \times 10^{1}$ & $2.1 \times 10^{2}$ & $7.6 \times 10^{-3}$ \\
& & 3 & $2.7 \times 10^{1}$ & $2.7 \times 10^{2}$ & $1.0 \times 10^{-3}$ \\
\hline \multirow{2}{*}{12} & Snow crust & 1 & $2.8 \times 10^{1}$ & $1.2 \times 10^{3}$ & $1.8 \times 10^{-1}$ \\
& Snow-covered pond & 2 & $8.7 \times 10^{0}$ & $9.4 \times 10^{3}$ & $6.6 \times 10^{-7}$ \\
& Crack & 3 & $2.3 \times 10^{0}$ & $1.2 \times 10^{4}$ & $4.4 \times 10^{-2}$ \\
\hline
\end{tabular}

that are beyond the initial framework of the model such as wet ice/snow, crusted snow, frozen cracks, and snow-covered ponds.

The statistical analysis of the measured data shows that the ordinary bare white ice has an optical thickness from 7 to 15 and an effective grain size of $1-4 \mathrm{~mm}$. However, the surface of white ice can be brighter, with unlimited optical thickness and smaller grains (from $400 \mu \mathrm{m}$ to $1 \mathrm{~mm}$ ). This surface is apparently a transition stage from fresh snow to an aged granular layer. Melting water-saturated ice forms a dark layer with an optical thickness of less than 5 and an effective grain size of $4 \mathrm{~mm}$ and larger (up to $10 \mathrm{~mm}$ ). Fresh snow usually has an optical thickness greater than 30 and an effective grain size less than $300 \mu \mathrm{m}$. All of these surfaces can contain some amount of the yellow substance (DOM from the seawater); however, in the case of fresh snow the possible 
pollutant can likely be from another source, such as an atmospheric aerosol, and the experimental evidence of the yellow substance presence in white ice may be a matter for further investigations.

The presented model has been successfully used in the retrieval of the sea ice albedo and melt pond fraction from satellite optical data (Zege et al., 2015; Istomina et al., 2015a, b). As a whole, the presented approach is going to be useful for developing various retrieval techniques of satellite remote sensing, for studying underwater light fields, and for the problems of physics of sea ice and marine biology of the Arctic Ocean.

\section{Data availability}

The field data utilized in Sect. 4 and shown in Figs. 8-12 are the spectral albedo of the Arctic surface measured during the R/V Polarstern cruise ARK XXVII/3. These spectra together with the photographs of the measurement sites can be accessed at the PANGAEA data repository under the reference Istomina et al. (2016).

Acknowledgements. The work was supported by the Seventh Framework Programme for Research and Development (project SIDARUS), financed by the European Union, and by the Junior Research Group for Remote Sensing of Sea Ice as part of the Institutional Strategy of the University of Bremen, funded by the German Excellence Initiative.

The authors are grateful to the scientific party of the ARK XVII/3 cruise for making the spectral albedo measurements possible. Special thanks are expressed to D. Perovich for providing the ASD FieldSpec Pro III, M. Nicolaus for organizing the logistics, and the Sea Ice Physics group on board for assisting with the measurements.

Edited by: J. Stroeve

Reviewed by: two anonymous referees

\section{References}

Aoki, T., Fukabori, M., Hachikubo, A., Tachibana, Y., and Nishio, F.: Effects of snow physical parameters on spectral albedo and bi-directional reflectance of snow surface, J. Geophys. Res., 105, 10219-10236, 2000.

Beine, H., Anastasio, FC., Domine, F., Douglas, T., Barret, M., France, J., King, M., Hall, S., and Ullmann, K.: Soluble chromophores in marine snow, seawater, sea ice and frost flowers near Barrow, Alaska, J. Geophys. Res., 117, D00R15, doi:10.1029/2011JD016650, 2012.

Bhatia, M., Das, S., Longnecker, K., Charette, M., andKujawinski, E.: Molecular characterization of dissolved organic matter associated with the Greenland ice sheet, Geochim. Cosmochim. Ac., 74, 3768-3784, doi:10.1016/j.gca.2010.03.035, 2010.

Boetius, A. and ARK-XXVII/3 Shipboard Scientific Party: List of sea ice measurements during Polarstern cruise ARKXXVII/3 (IceArc), Alfred Wegener Institute, Helmholtz
Center for Polar and Marine Research, Bremerhaven, doi:10.1594/PANGAEA.792734, 2012.

Boetius, A., Albrecht, S., Bakker, K., Bienhold, C., Felden, J., Fernández-Méndez, M., Hendricks, S., Katlein, C., Lalande, C., Krumpen, T., Nicolaus, M., Peeken, I., Rabe, B., Rogacheva, A., Rybakova, E., Somavilla, R., and Wenzhöfer, F.: RV Polarstern ARK27-3-Shipboard Science Party: Export of Algal Biomass from the Melting Arctic Sea Ice, Science, 339, 1430-1432, doi:10.1126/science.1231346, 2013.

Bogorodskii, V. V. (Ed.): The Physics of Ice, translated from Russian, Isr. Program for Sci. Transl., Jerusalem, 1970.

Bohren, C. F. and Barkstrom, B. R.: Theory of the optical properties of snow, J. Geophys. Res., 79, 4527-4535, 1974.

Bricaud, A., Morel, A., and Prieur, L.: Absorption by dissolved organic matter of the sea (yellow substance) in the UV and visible domains, Limnol. Oceanogr., 26, 43-53, 1981.

Byshuev, À., Volkov, N., and Loschilov, V.: Atlas of the Ice Formations, Hydrometeoizdat, Leningrad, 1974.

Choudhury, B. J. and Chang, A. T. C.: The solar reflectance of a snow field, Cold Reg. Sci. Technol., 1, 121-128, 1979.

Curry, J. A., Schramm, J. L., and Ebert, E. E.: Sea-ice albedo climate feedback mechanism, J. Climate, 8, 240-247, 1995.

Dethloff, K., Rinke, A., Benkel, A., Køltzow, M., Sokolova, E., Kumar Saha, S., Handorf, D., Dorn, W., Rockel, B., Storch, H. von, Haugen, J. E., Røed, L. P., Roeckner, E., Christensen, J. H., and Stendel, M.: A dynamical link between the Arctic and the global climate system, Geophys. Res. Lett., 33, L03703, doi:10.1029/2005GL025245, 2006.

Dobbins, R. A. and Jizmagian, G. S.: Optical Scattering Cross Sections for Polydispersions of Dielectric Spheres, J. Opt. Soc. Am., 56, 1345-1349, 1966.

Domine, F., Albert, M., Huthwelker, T., Jacobi, H.-W., Kokhanovsky, A. A., Lehning, M., Picard, G., and Simpson, W. R.: Snow physics as relevant to snow photochemistry, Atmos. Chem. Phys., 8, 171-208, doi:10.5194/acp-8-171-2008, 2008.

Eicken, H., Grenfell, T. C., Perovich, D. K., Richter-Menge, J. A., and Frey, K.: Hydraulic controls of summer Arctic pack ice albedo, J. Geophys. Res., 109, C08007, doi:10.1029/2003JC001989, 2004.

Gavrilo, V. P. and Gaitskhoki, B. Y.: The statistics of air inclusions in ice, in: The Physics of Ice, edited by: Bogorodskii, V. V., translated from Russian, Isr. Program for Sci. Transl., Jerusalem, 125$128,1970$.

Germogenova, T. A.: Some formulas to solve the transfer equation for a plane layer, in: Spectroscopy of light scattering media, Academy of Sciences of the BSSR, Minsk, 36-41, 1963.

Gille, W.: Chord length distributions and small-angle scattering, Eur. Phys. J. B, 17, 371-383, 2000.

Gille, W., Kabisch, O., Reichl, S., Enke, D., Fürst, D., and Janowski, F.: Characterization of porous glasses via small-angle scattering and other methods, Micropor. Mesopor. Mat., 54, 145-153, 2002.

Grannas, A., Pagano, L., Pierce, B., Bobby, R., and Fede, A. S.: Role of Dissolved Organic Matter in Ice Photochemistry, Environ. Sci. Technol., 48, 10725-10733, doi:10.1021/es5023834, 2014.

Grenfell, T. C. and Maykut, G. A.: The optical properties of ice and snow in the Arctic basin, J. Glaciol., 18, 445-463, 1977. 
Grenfell, T. C. and Warren, S. G.: Representation of a nonspherical ice particle by a collection of independent spheres for scattering and absorption of radiation, J. Geophys. Res., 104, 3169731709, 1999.

Grenfell, T. C., Warren, S. G., and Mullen, P. C.: Reflection of solar radiation by the Antarctic snow surface at ultraviolet, visible, and near-infrared wavelengths, J. Geophys. Res., 99, 18669-18684, 1994.

Hamre, B., Winther, J.-G., Gerland, S., Stamnes, J., and Stamnes, K.: Modeled and measured optical transmittance of snowcovered first-year sea ice in Kongsfjorden, Svalbard, J. Geophys. Res., 109, C10006, doi:10.1029/2003jc001926, 2004.

Hansell, D. A. and Carlson, C. A.: Biogeochemistry of marine dissolved organic matter, Academic Press, Amsterdam, 2014.

Hansen, J. E. and Travis, L. D.: Light scattering in planetary atmospheres, Space Sci. Rev., 16, 527-610, 1974.

Herzfeld, U. C., Maslanik, J. A., and Sturm, M.: Geostatistical Characterization of Snow-Depth Structures on Sea Ice Near Point Barrow, Alaska - A Contribution to the AMSR-Ice03 Field Validation Campaign, IEEE T. Geosci. Remote, 44, 3038-3056, 2006.

Istomina, L., Heygster, G., Huntemann, M., Schwarz, P., Birnbaum, G., Scharien, R., Polashenski, C., Perovich, D., Zege, E., Malinka, A., Prikhach, A., and Katsev, I.: Melt pond fraction and spectral sea ice albedo retrieval from MERIS data Part 1: Validation against in situ, aerial, and ship cruise data, The Cryosphere, 9, 1551-1566, doi:10.5194/tc-9-1551-2015, 2015a.

Istomina, L., Heygster, G., Huntemann, M., Marks, H., Melsheimer, C., Zege, E., Malinka, A., Prikhach, A., and Katsev, I.: Melt pond fraction and spectral sea ice albedo retrieval from MERIS data Part 2: Case studies and trends of sea ice albedo and melt ponds in the Arctic for years 2002-2011, The Cryosphere, 9, 15671578, doi:10.5194/tc-9-1567-2015, 2015b.

Istomina, L., Nicolaus, M., and Perovich, D. K.: Surface spectral albedo complementary to ROV transmittance measurements at 6 ice stations during POLARSTERN cruise ARK XXVII/3 (IceArc) in 2012, Institut für Umweltphysik, Universität Bremen, Bremen, doi:10.1594/PANGAEA.867292, 2016.

Kendall, M. G. and Moran, P. A. P.: Geometrical Probability, Griffin's Statistical Monographs and Courses. No. 5, C. Griffin, London, 1963.

Kerbrat, M., Pinzer, B., Huthwelker, T., Gäggeler, H. W., Ammann, M., and Schneebeli, M.: Measuring the specific surface area of snow with X-ray tomography and gas adsorption: comparison and implications for surface smoothness, Atmos. Chem. Phys., 8, 1261-1275, doi:10.5194/acp-8-1261-2008, 2008.

Kokhanovsky, A. A. and Zege, E. P.: Scattering optics of snow, Appl. Optics, 43, 1589-1602, 2004.

Kokhanovsky, A. A., Aoki, T., Hachikubo, A., Hori, M., and Zege, E. P.: Reflective properties of natural snow: approximate asymptotic theory versus in situ measurements, IEEE T. Geosci. Remote, 43, 1529-1535, 2005.

Køltzow, M.: The effect of a new snow and sea ice albedo scheme on regional climate model simulations, J. Geophys. Res., 112, D07110, doi:10.1029/2006JD007693, 2007.

Kopelevich, O. V., Lyutsarev, S. V., and Rodionov, V. V.: Spectral light absorption by yellow substance in seawater, Oceanology, 29, 305-309, 1989.
Lamare, M. L., Lee-Taylor, J., and King, M. D.: The impact of atmospheric mineral aerosol deposition on the albedo of snow \& sea ice: are snow and sea ice optical properties more important than mineral aerosol optical properties?, Atmos. Chem. Phys., 16, 843-860, doi:10.5194/acp-16-843-2016, 2016.

Light, B., Eicken, H., Maykut, G. A., and Grenfell, T. C.: The effect of included particulates on the spectral albedo of sea ice, J. Geophys. Res., 103, 27739-27752, 1998.

Malinka, A.: Light scattering in porous materials: Geometrical optics and stereological approach, J. Quant. Spectrosc. Ra., 141, 14-23, 2014.

Malinka, A., Zege, E., Katsev, I., Prikhach, A., Istomina, L.: Accounting for the effect of the atmosphere to interpret data of satellite and ground-based measurements of the Earth surface reflectance, J. Appl. Spectrosc., 83, in press, 2016.

Marks, A. A. and King, M. D.: The effect of snow/sea ice type on the response of albedo and light penetration depth (e-folding depth) to increasing black carbon, The Cryosphere, 8, 16251638, doi:10.5194/tc-8-1625-2014, 2014.

Massom, R. A., Eicken, H., Haas, C., Jeffries, M. O., Drinkwater, M. R., Sturm, M., Worby, A. P., Wu, X., Lytle, V. I., Ushio, S., Morris, K., Reid, P. A., Warren, S., and Allison, I.: Snow on Antarctic ice, Rev. Geophys., 39, 413-445, 2001.

Matzl, M. and Schneebeli, M.: Measuring specific surface area of snow by near-infrared photography, J. Glaciol., 52, 558-564, 2006.

Mobley, C. D.: Light and Water: Radiative Transfer in Natural Waters, Academic Press, San Diego, 1994.

Mobley, C. D., Cota, G. F., Grenfell, T. C., Maffione, R. A., Pegau, W. S., and Perovich, D. K.: Modeling Light Propagation in Sea Ice, IEEE T. Geosci. Remote, 36, 1743-1749, 1998.

Naumenko, Y. K.: The feasibility of obtaining data on the microstructure of an atmospheric aerosol by laser probing, Izv. Atmos. Ocean. Phy., 7, 605-608, 1971.

Nicolaus, M., Gerland, S., Hudson, S. R., Hanson, S., Haapala, J., and Perovich, D. K.: Seasonality of spectral albedo and transmittance as observed in the Arctic Transpolar Drift in 2007, J. Geophys. Res., 115, C11011, doi:10.1029/2009JC006074, 2010.

Norman, L., Thomas, D. N., Stedmon, C. A., Granskog, M. A., Papadimitriou, S., Krapp, R. H., Meiners, K. M., Lannuzel, D., van der Merwe, P., and Dieckmann, G. S.: The characteristics of dissolved organic matter (DOM) and chromophoric dissolved organic matter (CDOM) in Antarctic sea ice, Deep-Sea Res. Pt. II, 58, 1075-1091, doi:10.1016/j.dsr2.2010.10.030, 2011.

Nürnberg, D., Wollenburg, I., Dethleff, D., Eicken, H., Kassens, H., Letzig, T., Reimnitz, E., and Thiede, J.: Sediments in Arctic sea ice - Implications for entrainment, transport and release, Mar. Geol., 119, 185-214, 1994.

Perovich, D. K.: Light reflection from sea ice during the onset of melt, J. Geophys. Res., 99, 3351-3359, 1994.

Perovich, D. K.: The optical properties of sea ice, US Army Cold Regions Research and Engineering Laboratory (CRREL) Report 96-1, CCREL, Hanover, NH, USA, available at: httP; //www.dtic.mil/cgi-bin/GetTRDoc?AD=ADA310586 (last access: 24 March 2016), 1996.

Perovich, D. K., Grenfell, T. C., Light, B., and Hobbs, P. V.: Seasonal evolution of the albedo of multiyear Arctic sea ice, J. Geophys. Res., 107, C108044, doi:10.1029/2000JC000438, 2002. 
Perovich, D. K., Richter-Menge, J. A., Jones, K. F., and Light, B.: Sunlight, water and ice: extreme Arctic sea ice melt during the summer of 2007, Geophys. Res. Lett., 35, L11501, doi:10.1029/2008GL034007, 2008.

Perovich, D. K., Grenfell, T. C., Light, B., Elder, B. C., Harbeck, J., Polashenski, C., Tucker III, W. B., and Stelmach, C.: Transpolar observations of the morphological properties of Arctic sea ice, J. Geophys. Res., 114, C00A04, doi:10.1029/2008JC004892, 2009

Picard, G., Arnaud, L., Domine, F., and Fily, M.: Determining snow specific surface area from near-infrared reflectance measurements: Numerical study of the influence of grain shape, Cold Reg. Sci. Technol., 56, 10-17, 2009.

Pielou, E. C.: The spatial pattern of two-phase patchworks of vegetation, Biometrics, 20, 156-167, 1964.

Pirazzini, R.: Factors Controlling the Surface Energy Budget over Snow and Ice, Academic Dissertation in meteorology, Finnish Meteorological Institute, Helsinki, 2008.

Pistone, K., Eisenmann, I., and Ramanathan, V.: Observational determination of albedo decrease caused by vanishing Arctic sea ice, P. Natl. Acad. Sci. USA, 111, 3322-3326, doi:10.1073/pnas.1318201111, 2014.

Reimnitz, E., McCormick, M., McDougall, K., and Brouwers, E.: Sediment export by ice rafting from a coastal polynya, Arctic Alaska, U.S.A., Arct. Alp. Res., 25, 83-98, 1993.

Rösel, A., Kaleschke, L., and Birnbaum, G.: Melt ponds on Arctic sea ice determined from MODIS satellite data using an artificial neural network, The Cryosphere, 6, 431-446, doi:10.5194/tc-6431-2012, 2012.

Rozenberg, G. V.: Optical properties of thick layers of a homogeneous scattering medium, Smithsonian Institution, Astrophysical Observatory, Astronomical papers translated from the Russian, Iss. 9, ASIN: B0007F925C, 1966, Translated from Spectroscopy of light scattering media, Academy of Sciences of the BSSR, Minsk, 5-35, 1963.

Sea Ice Nomenclature: WMO No. 259, Suppl. No. 5, SPA_ETSI_manual_SIM02, available at: http:// www.ioc-unesco.org/index.php?option=com_oe\&task= viewDocumentRecord \&docID $=4438$ (last access: 24 March 2016), 2014.

Sellers, P. J., Meeson, B. W., Hall, F. G., Asrar, G., Murphy, R. E., Schiffer, R. A., Bretherton, F. P., Dickinson, R. E., Ellingson, R. G., Field, C. B., Huemmrich, K. F., Justice, C. O., Melack, J. M., Roulet, N. T., Schimel, D. S., and Try, P. D.: Remote sensing of the land surface for studies of global change: models - algorithms - experiments, Remote Sens. Environ., 51, 3-26, 1995.

Serreze, M. C., Walsh, J. E., Chapin III, F. S., Osterkamp, T., Dyurgerov, M., Romanovsky, V., Oechel, W. C., Morison, J., Zhang, T., and Barry, R. G.: Observational evidence of recent change in the northern highlatitude environment, Climatic Change, 46, 159207, 2000.

Serreze, M. C., Barrett, A. P., and Cassano, J. J.: Circulation and surface controls on the lower tropospheric temperature field of the Arctic, J. Geohpys. Res., 116, D07104, doi:10.1029/2010JD015127, 2011.

Shindell, D. and Faluvegi, G.: Climate response to regional radiative forcing during the twentieth century, Nat. Geosci., 2, 294-300, doi:10.1038/ngeo473, 2009.
Sobolev, V. V.: Light scattering in planetary atmospheres, Pergamon Press, Oxford, New York, 1975.

Switzer, P.: A random set process in the plane with a Markovian property, Ann. Math. Stat., 36, 1859-1863, 1965.

Thomas, D. N., Lara, R. J., Eicken, H., Kattner, G., and Skoog, A.: Dissolved organic matter in Arctic multi-year sea ice during winter: major components and relationship to ice characteristics, Polar Biol., 15, 477-483, 1995.

Thomas, D. N., Kattner, G., Engbrodt, R., Gianelli, V., Kennedy, H., Haas, C., and Dieckmann, G.: Dissolved organic matter in Antarctic sea ice, Ann. Glaciol., 33, 297-303, 2001.

Tomasi, C., Vitale, V., Lupi, A., Carmine, C. Di, Campanelli, M., Herber, A., Treffeisen, R., Stone, R. S., Andrews, E., Sharma S., Radionov, V., von Hoyningen-Huene, W., Stebel, K., Hansen, G. H., Myhre, C. L., Wehrli, C., Aaltonen, V., Lihavainen, H., Virkkula, A., Hillamo, R., Ström, J., Toledano, C., Cachorro, V. E., Ortiz, P., de Frutos, A. M., Blindheim, S., Frioud, M., Gausa, M., Zielinski, T., Petelski, T., and Yamanouchi, T.: Aerosols in polar regions: A historical overview based on optical depth and in situ observations, J. Geophys. Res., 112, D16205, doi:10.1029/2007JD008432, 2007.

Tschudi, M. A., Maslanik, J. A., and Perovich, D. K.: Derivation of melt pond coverage on Arctic sea ice using MODIS observations, Remote Sens. Environ., 112, 2605-2614, 2008.

Tynes, H., Kattawar, G. W., Zege, E. P., Katsev, I. L., Prikhach, A. S., and Chaikovskaya, L. I.: Monte Carlo and multicomponent approximation methods for vector radiative transfer by use of effective Mueller matrix calculations, Appl. Optics, 40, 400-412, 2001.

Untersteiner, N.: Structure and dynamics of the Arctic Ocean ice cover, in: The Arctic Ocean Region, edited by: Grantz, A., Johnson, L., and Sweeney, J. F., Geol. Soc. of Am., Boulder, Colorado, 37-51, 1990.

van de Hulst, H. C.: Radiative transfer in thick atmospheres with an arbitrary scattering function, Bull. Astron. Inst. Netherlands, 20, 77-86, 1968.

Warren, S. G.: Optical properties of snow, Rev. Geophys. Space Phys., 20, 67-89, 1982.

Warren, S. G.: Can black carbon in snow be detected by remote sensing?, J. Geophys. Res.-Atmos., 118, 779-786, doi:10.1029/2012jd018476, 2013.

Warren, S. G. and Brandt, R. E.: Optical constants of ice from the ultraviolet to the microwave: A revised compilation, J. Geophys. Res., 113, D14220, doi:10.1029/2007JD009744, 2008.

Wiebe, H., Heygster, G., Zege, E. P., Aoki, T., and Hori, M.: Snow grain size retrieval SGSP from optical satellite data: Validation with ground measurements and detection of snowfall events, Remote Sens. Environ., 128, 11-20, doi:10.1016/j.rse.2012.09.007, 2013.

Wiscombe, W. J. and Warren, S. G.: A model for the spectral albedo of snow. I. Pure snow, J. Atmos. Sci., 37, 2712-2733, 1980.

Zege, E., Katsev, I., Malinka, A., Prikhach, A., and Polonsky, I.: New algorithm to retrieve the effective snow grain size and pollution amount from satellite data, Ann. Glaciol., 49, 139-144, 2008.

Zege, E., Malinka, A., Katsev, I., Prikhach, A., Heygster, G., Istomina, L., Birnbaum, G., and Schwarz, P.: Algorithm to retrieve the melt pond fraction and the spectral albedo of Arctic summer ice 
from satellite optical data, Remote Sens. Environ., 163, 153-164, doi:10.1016/j.rse.2015.03.012, 2015.

Zege, E. P., Ivanov, A. P., and Katsev, I. L.: Image transfer through a scattering medium, Springer-Verlag, Heidelberg, 1991.
Zege, E. P., Katsev, I. L., Malinka, A. V., Prikhach, A. S., Heygster, G., and Wiebe, H.: Algorithm for retrieval of the effective snow grain size and pollution amount from satellite measurements, Remote Sens. Environ., 115, 2674-2685, 2011. 